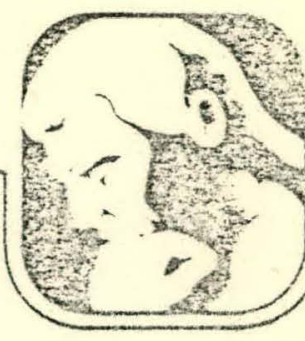

FOREIGN COAL LIQUEFACTION TECHNOLOGY SURVEY AND ASSESSMENT SASOL - THE COMMERICAL EXPERIENCE

\author{
PREPARED FOR \\ CHEMICAL TECHNOLOGY DIVISION OF \\ OAK RIDGE NATIONAL LABORATORY \\ SUBCONTRACT NO. 62B-13837C
}

BY

T.D.PAY

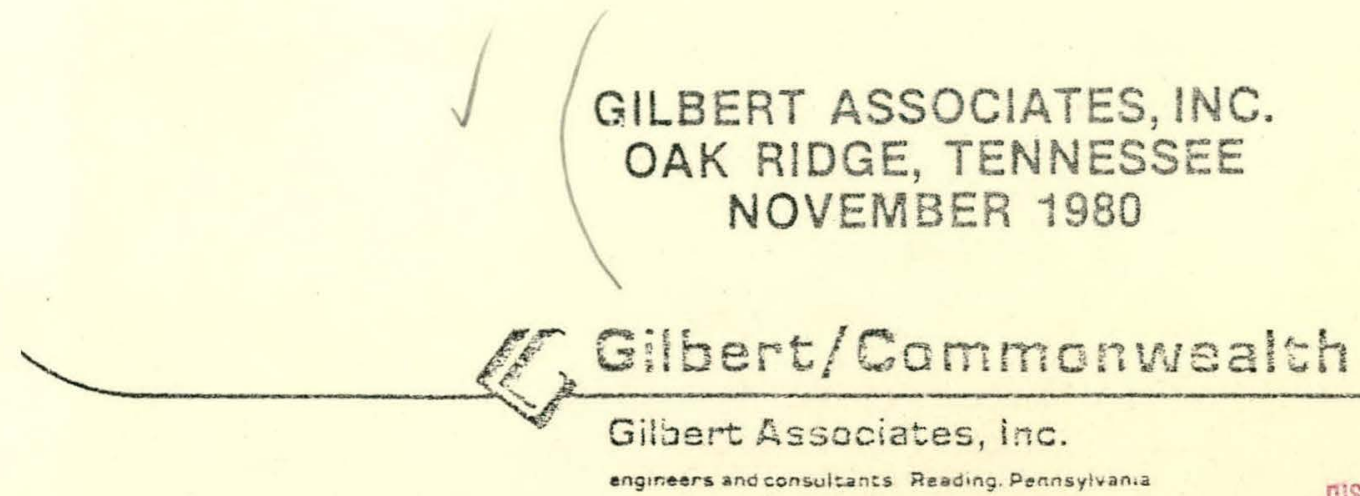




\section{DISCLAIMER}

Portions of this document may be illegible in electronic image products. Images are produced from the best available original document. 


\section{DISCLAIMER}

This report was prepared as an account of work sponsored by an agency of the United States Government. Neither the United States Government nor any agency Thereof, nor any of their employees, makes any warranty, express or implied, or assumes any legal liability or responsibility for the accuracy, completeness, or usefulness of any information, apparatus, product, or process disclosed, or represents that its use would not infringe privately owned rights. Reference herein to any specific commercial product, process, or service by trade name, trademark, manufacturer, or otherwise does not necessarily constitute or imply its endorsement, recommendation, or favoring by the United States Government or any agency thereof. The views and opinions of authors expressed herein do not necessarily state or reflect those of the United States Government or any agency thereof. 
Printed in the United States of America. Available from National Technical Information Service

U.S. Department of Commerce

5285 Port Royal Road, Springfield, Virginia 22161 NTIS price codes-Printed Copy: A06 Microfiche A01

This report was prepared as an account of work sponsored by an agency of the Uniled States Government. Neither the United States Government nor any agency thereot, nor any of their empioyees, makes any warranty, express or implied, or assumes any legal liability or responsibility for the accuracy, completeness, or usefulness of any information, apparatus, product, or process disclosed, or represents that its use would not intringe privately owned rights. Reterence herein to any specific commercial product, process, or service by trade name, trademark. manufacturer, or otherwise, does not necessarily constitute or imply its endorsement, recommendation, or favoring by the United States Government or any agency thereot. The views and opinions of authors expressed herein do not hecessalily slate or ieflect those of the Unitod Stated Government or any agenry thereol. 


\title{
FOREIGN COAL LIQUEFACTION TECHNOLOGY SURVEY AND ASSESSMENT SASOL - THE COMMERCIAL EXPERIENCE
}

\author{
BY \\ T. D. PAY \\ GILBERT ASSOCIATES, INC. \\ Oak Ridge, Tẹnnessee \\ Work sponsored by the \\ International-Energy Technology \\ Assessment Project, directed by \\ Lawrence Livermore National Laboratory
}

Prepared under

Subcontract No. 62B-13837C

For Chemical Technology Division

Oak Ridge National Laboratory

Oak Ridge, TN 37830

Operated by

Union Carbide Corporation

for the

U.S. Department of Energy

Contract No. W-7405-eng-26

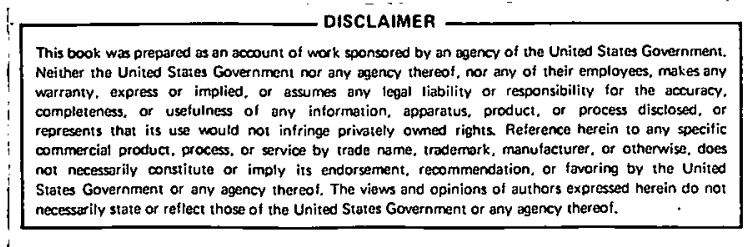

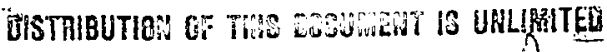

1 
Section

No.

1.0

1.1

1.2

2.0

2.1

2.2

2.3

2.4

2.5

2.6

2.7

2.8

2.9

3.0

3.1

3.2

3.3

3.4

3.5

3.6

3.7

Title

Page

SUMMARY

INTRODUCTION

Corporate History

3

Corporate Structure

SASÖL ONE

Cual and sigma Mine 11

Gasification, Phenosolvan, and Tar Refining.

Gas Purification and Methane Reforming

Synthol Synthesis and Product Refining

Arge Synthesisi and Product Refining

Shift Conversion, Ammonia Synthesis and Fertilizer

Gas Blending and Distribution

58

Oxygen, Nitrogen, Steam and Water

olefin complex

66

68

SASOL TWO

70

Coal and Bossjesspruit Mine

71

Gasiffcation, Phenolsolvan, and Tar Refining

7.6

Gas Purification and Methane Reforming 77

Synthol Synthesis $\quad 80$

Product Refining $\quad 84$

Oxygen, Steam and Water . 86

4.0

SASOL-THREE

87

REFERENCES

89 
Figure No:

1,1

2.1

2.2

2.3

2.4

2.5

2.6

2.7

2.8

2.9

2.10

2.11

2.12

2.13

$2: 14$

2.15

3.1

3.2
Title

Page

Sasol Group Financing

4

Sasol. Flow Sheet 8

Sasol's Profit History . 9

Mark 4. Lurgi Gasifier 1.5

Temperatures and Composttions in Lurgi Gasifier 19

Pure Gas Sulfur Levels during Sasol One Operating Hịtory

27

Synthol Reactor 34

Synthol Synthesis $\mathrm{CO}+\mathrm{CO}_{2}$ Conversion 38

Synthol Synthesis Useful Product Yield 39

Light Oil and Decanted Oil ASTM Distillations 43

$\begin{array}{ll}\text { Arge Reactor } & 49\end{array}$

AIge Product Refining $\quad 54$

Shift Converter, Amonia, Fertilizer and Synthol Loop

Daily Fluctuations in Gas Demand 61

Seasonal Fluctuations in Gas Demand . 62

Synthol and Arge Capacities $\quad 63$

Sasol Two Flow Sheet $\quad 72$

Design and Construction Schedule for Sasol Two 73 
Table No.

1.1

2.1

2.2

2.3

2.4

2.5

2.6

2.7

2.8

2.9

2.10

2.11

2.12

2.13

3.1

3.2

3.3

3.4
Sasol One Subsidiaries

Sigma Coal Properties

Typical Coal Size for Lurgi Gasifiers

Raw Gas Compositions

Crude Phenol Composition

Reformed Gas Composttion

Synthol Selectivities - Commercial Results

Carbon Atom Distribution for Synthol Light 0 il and Decanted Oil

Non-acid Chemicals and Organic Acids Composition

Synthol Tail Gas Composition

Comparison of Arge and Synthol Processes

Comparison of Gasoline and Diesel from Arge and Synthol

Arge Tail Gas Composition

Industrial Gas Blending Components and Their Energy Contents

Bósjesspruit Coal Properties

Raw Gas Composition - Sasol Two

Pure Gas Composition - Sasol Two

Product Selectivity for the Sasol Two Synthols
6

12

16

20

24

32

42

44

45

4.

5




\section{SUMMARY}

An effort has been made to sift through the numerous documents that have been published concerning the Sasol facilities in Sasolburg and Secunda, South Africa, and compile a report that will describe these facilities in some detail and in a logical fashion. The report is split into a section on Sasol One and a smaller one covering Sasols Two and Three.

The description of Sasol One is essentially a description of the cumercial plant. Ihe second section describes what has been done in recent years, is being done now and is planned for the near future to use the experience that has been gained by Sasol Itd. since 1955 in new synthetic fuels facilities that addresses the energy problems of South Africa in the 1980's.

In each section the format is the same. The coal is followed from the mine through the various process units to the products that are marketed b.y. Sasol. Also described are some of the major ancillary units that are key to these facilities. These include steam. raising, oxygen production and catalyst preparation. Mention is also made of the other Sasol plants which, although not coal based, are integrated with the synthetic fuels facilities.

In this introductory section mention is made of the key role that Sasol plays in the entire South African energy scene and the catalyst that it has been in forming a diverse chemical industry in the Sasolburg area. 
Blank

vii 


\section{$1.0 \quad$ INTRODUCTION}

1.1 . CORPORATE HISTORY

As far back as 1927 the South African government had noted the country's heavy dependence on imports for much needed transportation fuels. This was when a White Paper had been published on oil-from-coal. Here was a way to make use of the country's bountiful coal reserves (estimated at at least 90 billion metric tons between 15 and $400 \mathrm{~m}$ below the surface ${ }^{1}$ ) thereby cutting dependence on foreign fuel sources.

Anglo Transvaal Consolidated Investment Ltd (Anglovaal) did much of the pioneering work in this field. ${ }^{2,3}$ In 1935 they acquired the South African rights to the German F-T processes, 4 and in 1945 the rights to the Hydrocol process. 5 The government helped further interest in the field by laying out the legislative frame work for an oil-from-coal industry - the Liquid Fuel and Oil Act of 1947. The Iiquid Fuel and Oil Industry Advisory Board granted Angloval a license to manufacture oil from coal in January 1948. Because of Angloval's involvement in developing more gold mines, doubts were expressed about its ability to raise the capital needed. Negotiations with the South African Govermment were held and in 1950 it was agreed that the government would take over these rights. The South African Coal, Dil and Gas Corporation Limited was formed with funding coming from the treasury via the Industrial Development Corporation (IDC). The IDC is the state corporation that has provided much of the venture capital to such high risk projects.

Thus started a venture which built a factory and an associated new town. These developed in such a way that Sasol, as the company became known, was the hub of a coal-based industry which has grown to the point that it has the attention of the whole world. Sasolburg is now the center of the South African 
chemical industry and Sasol not only manufactures and markets directly fuels and chemical from coal, but it is a major raw material supplier to other industries around its periphery and has itself, diversified into many energy related activities.

In order to give some idea of how Sasol has stimulatcd other industries a section of the company's propectus offering shares to the public is quoted: 6

"The manufacture of a wide range of intermediary chemical products by Sasol One brough about the establishment of several satellite industries at Sasolburg resulting in it becoming the most important centre in the South African chemical induetry. Feed etocke euch as othylone, propylene, butadiene and styrene, of which Sasol One is the only manufacturer in the country, are supplied to these satellite industries.

AECI Limited has already established two large factories, Coalplex (in association with Sentrachen Limited) and Midland, at Sasolburg for the manufacture of plastics and other chemical products. These factories make use of a variety of feed stocks acquired from Sasol One.

Karbochem (Proprietary) Limited, a wholly-owned subsidiary of the Sentrachem group, manufactures a wide range of products by processing feed. stocks which are mainly supplied by Sasol One. Synthetic rubber, for example, is manufactured from styrene and butadiene produced by Sasol One.

Safripol (Proprietary) Limited, owned by Sentrachem Iimited and Hoechst SA (Proprietary) limited, uses the ethylene and propylene supplied by Sasol One for the manutacture of high-density polyethylene and polypropylene respectively for the plastics industry.

The manufacture of nitrogenous feed stocks such as sulphate of ammonia, ammonia, ammonium nitrate, limestone ammonium nitrate, nitric acid and sulphur by Sasol One resulted in the establishment of fertiliser factories at Sasolburg by Federale Kunsmis Limited and Omnia Fertilisers Limited.

In addition to the feed stocks which are supplied to the neighboring industries, Sasol One also provides utilities such as steam and fuel gas to almost all the industries established in Sasolburg. 
In the foreseeable future the development of satellite industries which make use of chemical feed stocks of the Sasol group will still take place mainly at Sasolburg. Ethylene, which will be one of the most important feed stocks supplied by Sasol Two, will be transported to Sasolburg from Secunda by means of a gas pipeline which has almost been completed."

The Coalplex facility above is itself a coal based chemical complex where PVC and other plastics are produced.

Over the three decades of its existance the Sasol group has grown from an oil-from-coal facility for producing linuid fuels with the associated mine to an organization that now has three of these facilities (Sasol Two is in the commissioning phase while Sasol Three's construction is well under way), two coal mines, an olefins complex, a major portion of a crude oil refinery and a gas pipeline. All of these are operated in a mutually compatable way that has made Sasol a true "energy company".

\subsection{CORPORATE STRUCTURE}

For most of its corporate life the South African Coal, 0 il and Gas Corporation, Limited had one owner of its share capital - the Industrial Development Corporation. The IDC also supplied some of the loan capital requirements that allowed Sasol to expand its activities over the years. When Sasol started making money the IDC was the sole recipient of the profits.

All this changed in $1979 .^{5}$ The company was restructured into four separate companies. Sasol limited is the new holding company, in which the public has a $70 \%$ stake and the government, through the IDC, has $30 \%$. The old South African Coal, Oil and Gas Corporation (Sasol) is now known as Sasol One and is a wholly owned subsidiary of Sasol Ltd. (Fig. 1.1). ${ }^{6}$ The Sasol One subsidiaries are the companies which give the group its diversity in the energy business. Table 1.1 lists these subsidiaries and their principal activities. 


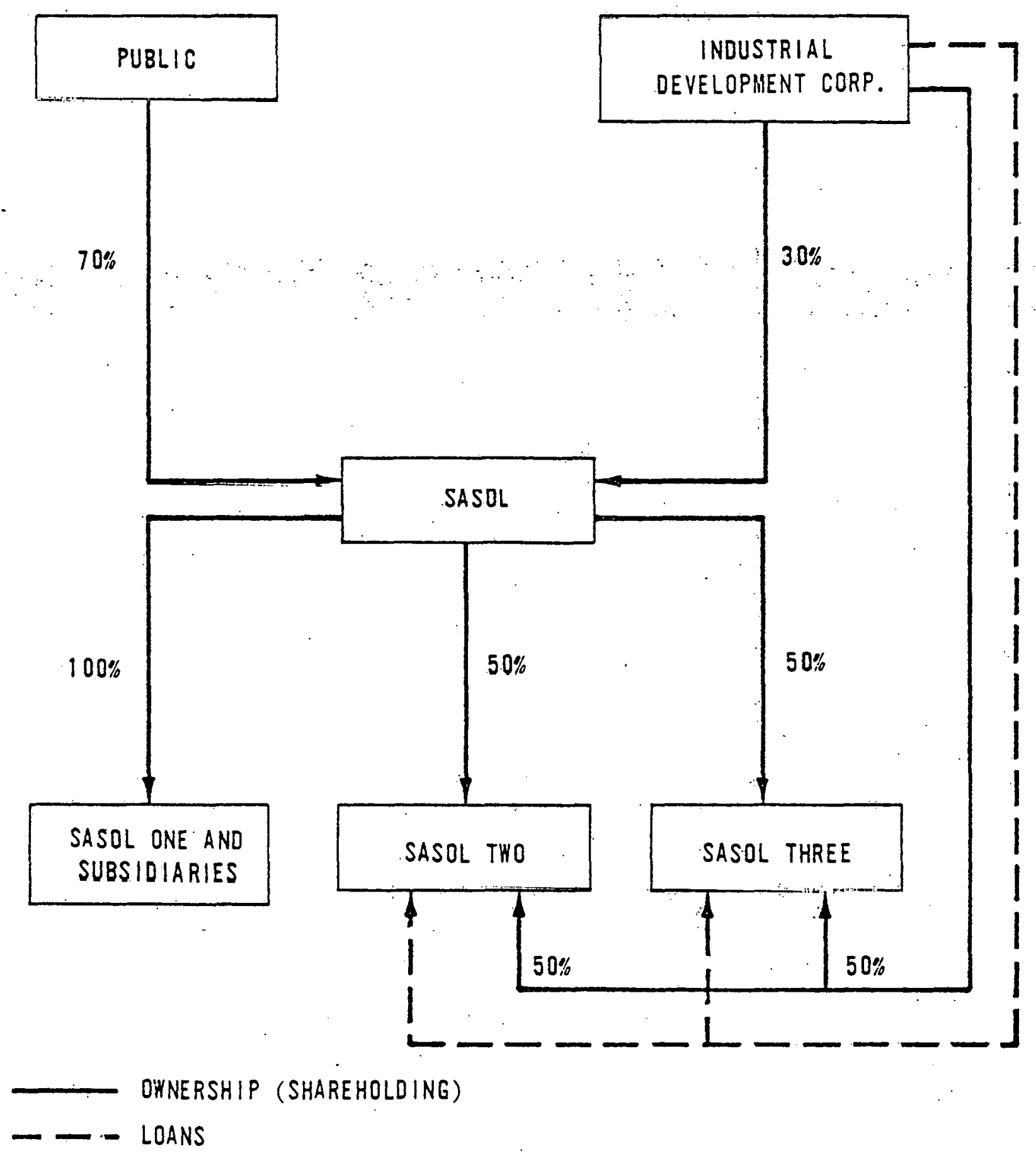

FIGURE 1.1

SASOL GROUP FINANCING

REFERENCE (6) SASOL 
Sasol Two and Sasol Three are the companies that will operate the group's second and third oil-from-coal facilities. Both companies are jointly owned by Sasol Ltd. and the: IDC. There is a strong hint that the public ownership of these companies could increase through future share issues.

Although not mentioned in Table 1.1 the Sasol group also oversees South Africa's strategic petroleum reserve.?, 8 Several. worked out underground coal mines as well as surface tank farms were pressed into service storing enormous (by South African standards) quantities ${ }^{9}$ of crude oil bought years ago at a fraction of today's prices. 
Table 1.1 Sasol One Subsidiary Companies 6

1. Sasol Marketing Company (SMC) - Markets petroleum products of the Sasol group excluding road binder material, tar and bitumen.

2. South African Gas Distribution Corporation (Gascor) - Distributes industrial gas by pipeline from Sasol One to the industrial complex of the Witwatersrand and Vaal Triangle. It has also been designated as the distributor of any natural gas that may be discovered in South Africa.

3. National Petroleum Refiners of South Africa (Natref) - Refines crude oil. which is pumped by pipeline from the coast 600 kn away for Sasol One into IPG, gasoline, diesel oil, kerosene, jet fuel, bitumen and other products. Sasol One owns $52.5 \%$. The other partners are. . the National Iranian 0 il Company (NIOC), $17.5 \%$ and Compagnie Francaise des Petroles (Total), 30\%.

4. Sasol Dorpsgebiede (SDB) - Undertakes township development at Sasolburg and provides housing for the Sasol group's employees.

5. Inspan Beleggings - Holds the major portion of the coal rights of Bosjesspruit's coal fields.

6. Leslie Coal Development Company - Holds Sasol One's longer-term coal rights.

7. Allied Tar Acid Refiners (Atar) - Refines tar acids in one of Sasol One's factories. Atar also markets phenols and cresylic acid through SMC.

8. Tosas - Holds a $50 \%$ interest in FTS Binders which in turn markets road binder material, tar and bitumen.

9. Southern 0il Exploration Corporation (Soekor) - Sasol One has a 50\% share of Soekor which is to lead and coordinate the search for oil in South Africa on behalf of the government with state funds.

10. Fedgas - Markets industrial gases such as oxygen nitrogen and argon some of which are supplied by Sasol One. Sasol One has a $20 \%$ interest in Fedgas.

11. Inspan Bedryf, Sasol Konstruksiemaatskappy and Naftachem are dormant . companies. 
$2.0 \quad$ SASOL ONE

An examination of the Sasol One flow sheet (Figure 2.1) immediately calls to attention the large number of process units that have been put together over the past 25 years to make this unique synthetic fuels fac1licy. That all these units function together profitably ${ }^{5}$ (Fig. 2.2) in an integrated and complementary way is a tribute to the perseverance of the operating staff. It wasn't always that way. ${ }^{1}$

The whole indirect Iiquefaction grocess at Sasol One (Fig. 2:1) starts with the coal, steam and oxygen being gasified. The coal is from the adjacent Sigma mine, the oxygen is produced in the air separation unit and the steam is raised in the pulverized coal boilers of the steam plant that uses the fine fraction of the coal. The liquid produced by the gasifiers is separated into tars and oils, which are then distilled into solvents, creosotes and road tars, and gas liquor, an aqueous stream, from which ammonia and tar acids are recovered at the Phenosolvan plant.

The gas product from the gasifiers, raw gaș, enters the Rectisol gas purification plant where carbon dioxide and hydrogen sulfide are removed leaving the synthesis gas known as pure gas. There are a number of places where this pure gas can be used. The principal destinations are the two Fischer-Tropsch synthesis units in the Arge (fixed bed) and Synthol (entrained bed) plants." These synthesis units produce a wide spectrum of hydrocarbons andoxygenated compounds. The liquid streams are refined into saleable products in the refineries associated with each synthesis plant.

Gas that is not converted in the synthesis units may be blended into the industrial gas that is distributed by the Gascor system or it can be scrubbed to remove carbon dioxide and fed to the partial oxidation reformers to be converted into more Synthol feed. Some of the Synthol tail gas joins a pure gas stream that has undergone water gas shift, 
COAL. TONAE (AS RECE IVEO FROM HINE I HOISTURE: 10. BE

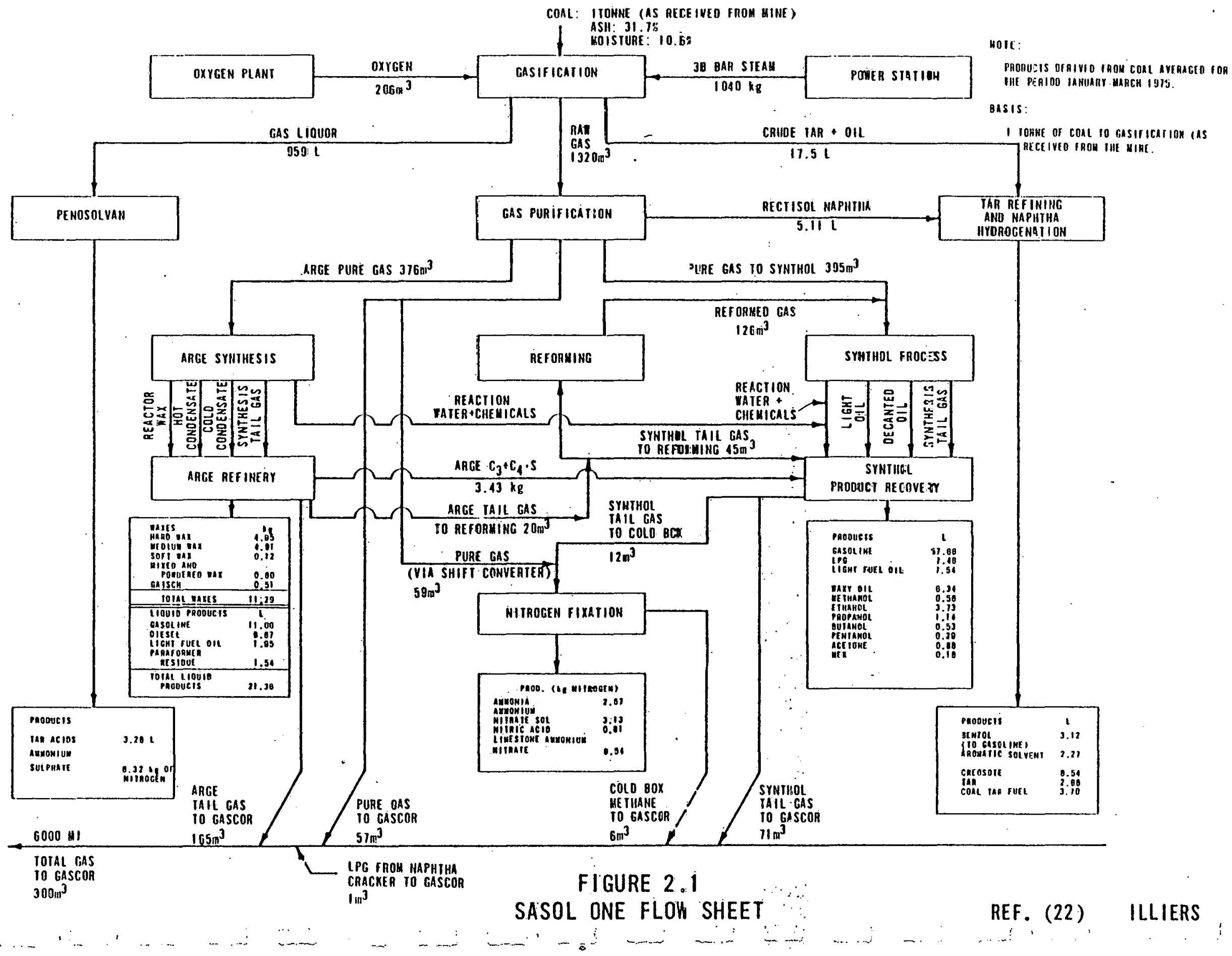




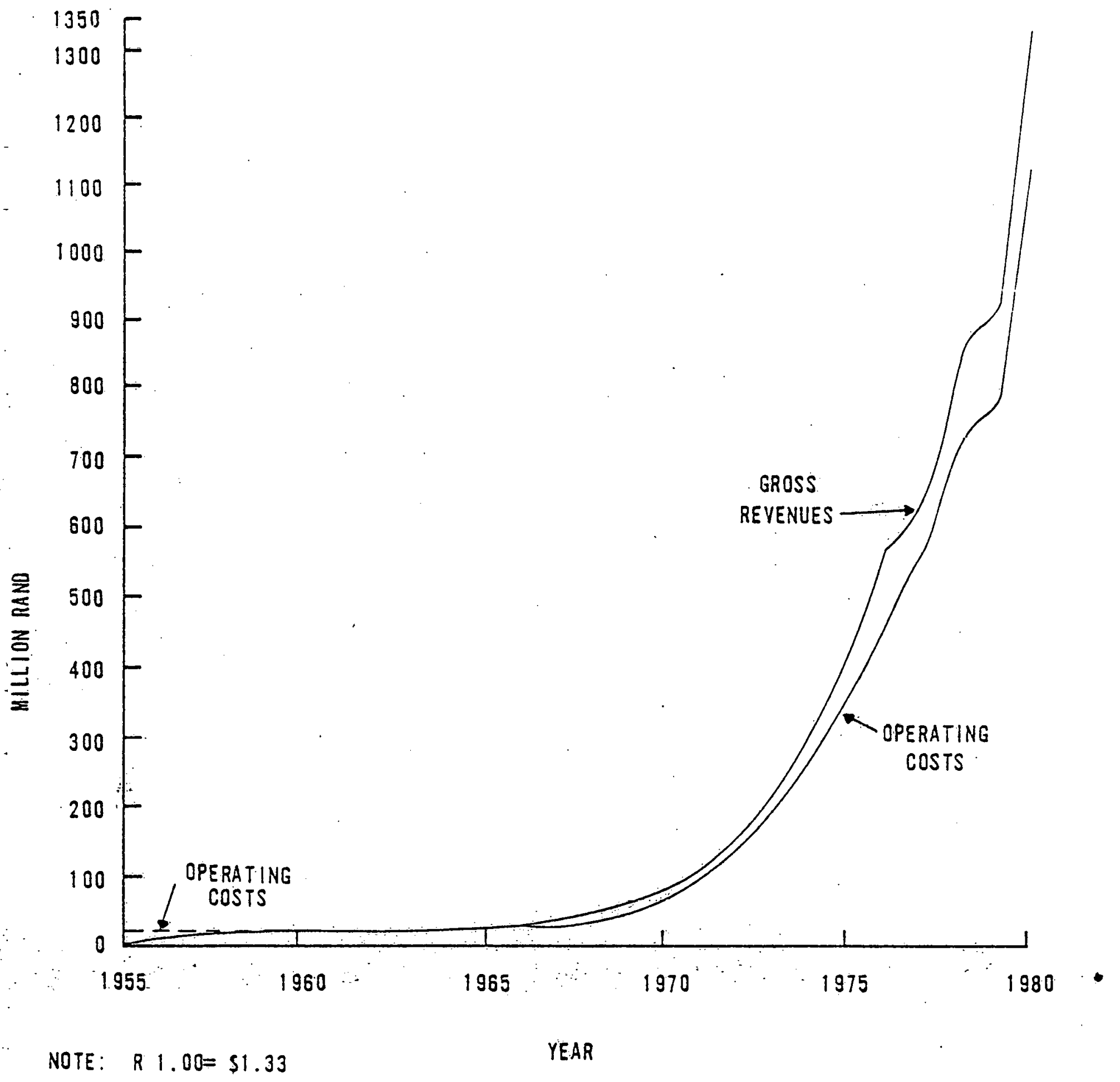

FIGURE 2.2

SASOL'S PROFIT HISTORY

REFERENCE (5) FINANCIAL MAIL 
to become feed for the ammonia synthesis units after carbon dioxide and hydrocarbon removal. The nitrogen for the ammonia is a byproduct of the air separation unit. The remainder of the nitrogen fixation area converts this ammonia to ammonium nitrate, nitric acid and limestone ammonium nitrate.

Linked to the oil-from-coal part of the Sasol One facility by fuel gas, liquefied petroleum gas (IPG) and gasoline systems is the olefin section. Here two naphtha crackers produce ethylene for the plastics industry and styrene and butadiene plants produce raw materials for the synthetic rubber industry.

The physical plant is located at Sasolburg in the Highveld region of South Africa. ${ }^{4}$ It lies $80 \mathrm{~km}$ south of Johannesburg and $600 \mathrm{~km}$ inland from the major port of Durban. It is on the southern fringe of the Pretoria-Witwatersrand-Vaal Triangle area which, as the industrial and mining heartland of South Africa, is the Sasol Group's primary market area. The fflat to gently sloping land for the plant is $1400 \mathrm{~m}$ above sea level and $8 \mathrm{~km}$ south of the Vaal River which is the plant's water supply. The land requirement for the factory is an area approximately $1.5 \mathrm{~km}$ by $0.6 \mathrm{~km}$ with about $1.5 \mathrm{~km} \times 0.5 \mathrm{~km}$ additional land used for the coarse and fine ash disposal.

The Sigma Colliery lies $1.5 \mathrm{~km}$. southwest of the plant and is connected to it by conveyor belts.

Adjacent to the Sasol works lies the Natref refinery about $1.0 \mathrm{~km}$ east and the peripheral industrial mentioned in Section 1.1 to the east and southeast. To the northwest and south are the residential areas of Sasolburg which has a population of 35,000 . The climate is good with summer high temperatures around $35^{\circ} \mathrm{C}$ and winter lows of $-3^{\circ} \mathrm{C}$. Rainfall of $600 \mathrm{~mm}$ falls almost entirely in summer. 
The Sasol One plant gets its coal from the nearby Sigma mine. The coal rights are owned for about 19,500 hectares in the area. ${ }^{6}$ Options are owned on a further 3,300 hectares. In situ reserves are on the order of 1 billion tons. The coal is low grade and is mined at a depth of about 150 m below the surface ${ }^{4}$ using both room and pillar and long-walling methods. ${ }^{10}$ The properties of Sigma coal are given in Table $2.1 .4,11,12$

Shaft sinking for the mine started in $1951 .^{3}$ There are now three ventilation shafts, three vertical shafts to move men and materials and two inclined shafts to bring out the coal. Production at the mine has reached $5.5 \mathrm{Mt} / \mathrm{y}^{5}$ with the long-walling now contributing some $1.9 \mathrm{Mt} / \mathrm{y}$. To do this 1800 people are employed.

The coal is present in three seams. ${ }^{2}$ No. 1 , at the bottom, is the oldest and the most undulating. The seam thickness is $3 \mathrm{~m}$. The middle seam whose thickness varies considerably, is split in the $2 A$ and $2 B$ subseams of $2.4 \mathrm{~m}$ and $3 \mathrm{~m}$ mining heights. Most of the coal requirements are produced from the No. 2 seam. The No. 3 seam has a mining height of $2.7 \mathrm{~m}$ and is 12 to $25 \mathrm{~m}$ above the No. 2 seam.

Present practice with the room and pillar mining is to cut $6 \mathrm{~m}$ by $2.7 \mathrm{~m}$ roadways on $20 \mathrm{~m}$ centers. Pillars of $14 \mathrm{~m}$ square are left to support the roof. No attempt is made to mine two seams at the same grid location.

The primary crushers are situated at the base of the inclined shafts and receive the raw coal from the face on $1.2 \mathrm{~m}$ wide trunk conveyors. Similar sized conveyors $450 \mathrm{~m}$ long move the coal to the surface up to $18^{\circ}$ inclined shaft where storage bunkers give 
Table 2.1 Typical Sigma Coal Analysis $4,11,12$

\section{Type}

Moisture (as received)

Volatiles (dry basis)

Ultimate Analysis (dry basis), wt \%

Ash

Sulfur

Nitrogen

Carbon

Hydrogen

oxygen

10.7 wt $\%$

22.3 wt $\%$

35.9

0.5

1.2

50.8

2.8

8.8

Ash Fusion Temperature, ${ }^{\circ} \mathrm{C}$ :

Softening point

Meleing point.

1430

Fluid point

1475

Energy Content, MJ/kg (dry) 
about 1 day's holding capacity before the secondary crushers and screens. ${ }^{13}$ The final product consists of two coal sizes: $-12 \mathrm{~mm}$ and 12-50 $\mathrm{mm}$. These are transferred to Sasol One along twin, $2.0 \mathrm{~km}$ long conveyors. There is bunker and silo storage at the factory for about 2-3 days. The fines go to the two power plants while the coarse material is destined for the gasifier. The split is about 40:60. 
2.2 GASIFICATION, PHENOSOLVAN AND TAR REFINING

The gasification plant has 16 Lurgi dry ash gasifiers. Thirteen of them are Mark 3's with an internal diameter of $3.68 \mathrm{~m}$ and the remaining three Mark 4's that were installed in 1977/1978 have an internal diameter of $3.85 \mathrm{~m} \cdot{ }^{11,12}$ There was a plan to install one $4.9 \mathrm{~m}$ ID $(5.0 \mathrm{~m} \mathrm{OD})^{14}$ Mark 5 gasifier as an experimental rig but execution seems to be slow. ${ }^{15,16}$ The $12.5 \mathrm{~m}$ long, 202 tonne gasifier vessel arrived at the Sasol One site in May $1980 .^{14} \mathrm{~A}$ significant difference between the Mark 3 and Mark 4 is the method of driving the grate. In the older gasifiers the motor is located at the top and drives the grate at the bottom of the reactor vessel via a large vertical shaft. In the Mark 4 gasifier this shaft has been removed by placing the grate drive motor at the bottom and having it drive the outer edge of the grate ${ }^{17}$ (Fig. 2.3). The removal of the shaft provides increased reactor volume.

Coal is brought by conveyor belt from the storage bunkers and screened once more before it enters the hoppers above each gasifier. Any fine material (less than $12 \mathrm{~mm}$ ) is routed to the pulverized coal boilers at the power plant: Table 2.2 gives a typical coal size for the Lurgi gasifiers. The coal enters a coal lock at the top of the gasifier from the hoppers. For the older equipment these locks hold 6.5 tonnes and filling takes 7-8 minutes. 13 The newer equipment on the Mark 4 gasifier is bigger - probably 10 tonnes capacity - in order to handle the larger loads. After pressurizing the charge in the coal lock with raw gas, the coal gravitates through the conical valve and is distributed in the reactor. During depressurization the gas from the coal lock is routed to a gas holder and then flared.

The jacket of the gasifier is water cooled and the steam that is generated joins other high pressure (3.9 MPa) steam which is mixed with oxygen. This mixture enters the bottom of the gasifier through three pipes and is distributed into the fuel bed between the grate sections at three circumferences thus cooling the entire grate. 


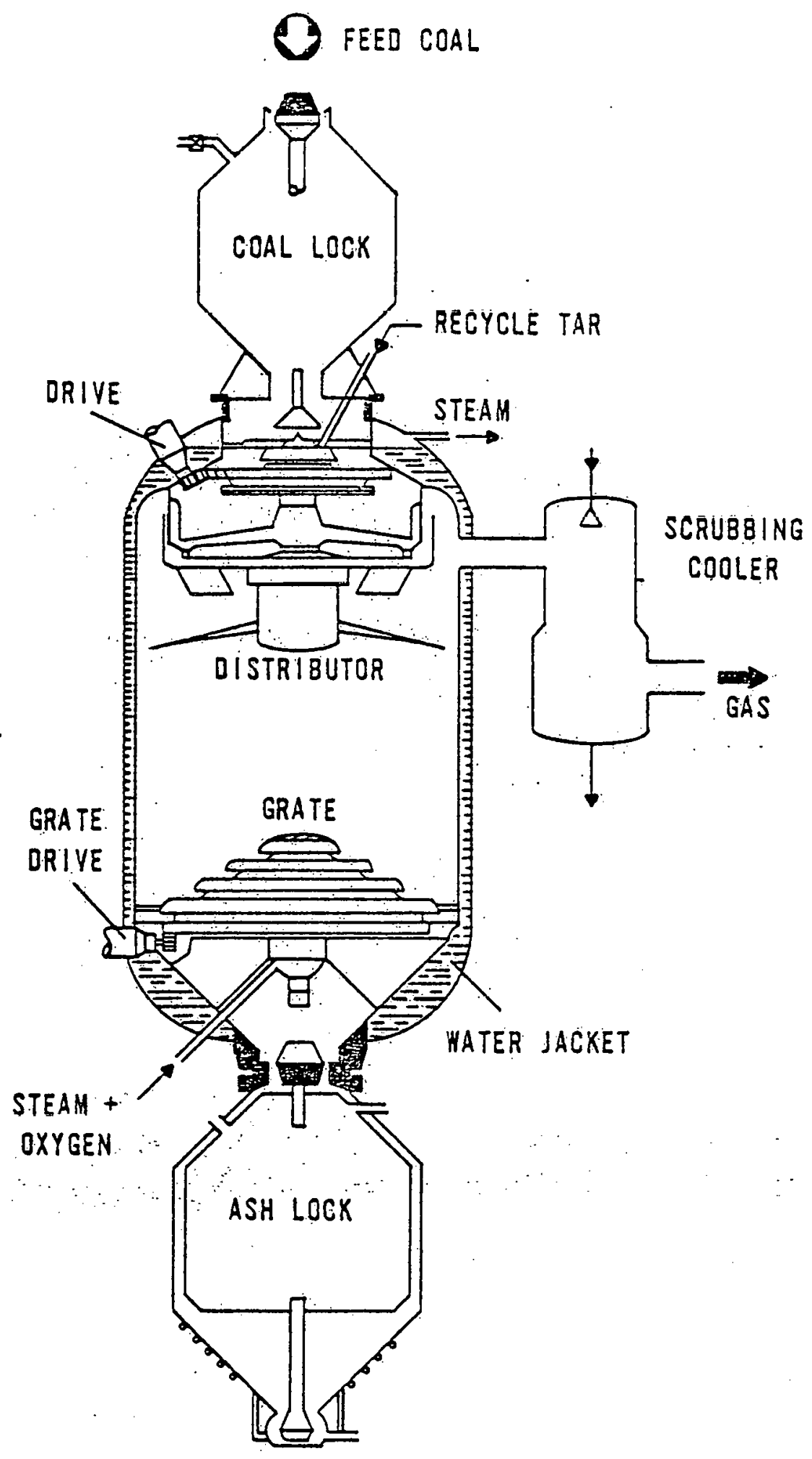

FI'GURE 2.3

MARK IV LURGI GASIFIER

REFERENCE (17) RUDOLPH 
Table 2.2 Typical Coal Size for Lurgi Gasifiers 11

$$
\begin{array}{r}
+38 \mathrm{~mm} \\
25-38 \mathrm{~mm} \\
12-25 \mathrm{~mm} \\
6-12 \mathrm{~mm} \\
-6 \mathrm{~mm}
\end{array}
$$

$8 \%$
$32 \%$
$47 \%$
$8 \%$
$5 \%$


The ash lock is pressurized with high pressure superbeated steam and the ash is then discharged into it from the gasifier. After depressurizing, the ash at about $400^{\circ} \mathrm{C}$ drops out through the conical valve and is sluiced away, ${ }^{18}$ There have been no really successful attempts to pump the ash to the disposal area. Erosion of impellers and in steel pipes. is great. ${ }^{19}$ This is not surprising when it is considered that each Mark 3 gasifier produces at 200 tons/day of ash and 350 tons/day for the Mark 4's. Much attention has been paid to the performance and problems of the ash removal system, especially the part downstream of the ast locks. With proper design of components and good maintenance the availability of the whole ash removal system has been increased from $50 \%$ to more than $9.9 \%$. ${ }^{19}$ Because of the very erosive environment at the bottom of the gasifier, grates and ash lock cone and seat valves are items that receive much maintenance.

Ash is water sluiced to the treatment area by an elevated, gently-inclined, ceramic-lined sluice-way or "ashqueduct." The coarse ash is. separated from the fine by water classification. 18 The coarse ash is taken by conveyor directly to a nearby dump where it is allowed to dry by natural evaporation. The fine ash is thickened in large circular thickening ponds and is pumped to a sludge pond nearby. The sludge pond has an impervious clay bed and water draining through the pond area is caught in a catchment basin and treated before being released to the environment. The coarse ash pile (about $50 \mathrm{~m}$ high) has had the static faces revegetated by judicious use of grasses, fertilzer and irrigation.

Overall availability of the gasifier plant is about $85 \%$ and to achieve this at most only two gasifiers can be off line. 11 Here is where the large maintenance effort is needed. Maintenance scheduling is determined primarily by the wear of the ash lock system 
and a 3-month schedule is generally followed. An annual feed (coal) hopper maintenance is carried out. Government required pressure lest schedules have bccn extended by experience, to the point where a complete reconditioning is required only after a three year interval. 18

Gasification is carried out at $2.6 \mathrm{MPa}$. Temperatures and compositions found within the reactor are shown relative to vertical position in Figure 2.4. ${ }^{17}$ The $\mathrm{H}_{2} / \mathrm{CO}$ ratio in the raw gas can be adjusted by control of the steam/oxygen ratio fed to the gasifier. 13 Raising the steam/oxygen ratio "cools" the system and produces higher $\mathrm{H}_{2} / \mathrm{CO}$ ratios. This is how the two header raw gas system can be supplied with the appropriate gas. One header has the Synthol raw gas with $\mathrm{H}_{2} / \mathrm{CO}$ ratios of about 2.15 and the other hids Arge raw gas where the ratio is about 1.85. Raw gas compositions are given in Table 2.3. ${ }^{20}$ Typical steam/oxygen ratios vary between 4.65 and $5.86 \mathrm{~kg} \mathrm{H} 2 / \mathrm{m}^{3 *} \mathrm{O}_{2} .17$

Oxygen consumption is in the region of $1.56 \mathrm{~m}^{3} / 1000 \mathrm{~m}^{3}$ of raw gas. High pressure steam used is about $730 \mathrm{~kg} / 1000 \mathrm{~m}^{3}$ raw gas. On the other hand raw gas production is about $2250 \mathrm{~m}^{3} /$ tonne dry; ash free coal. 11

Each Mark 3 unit handles about $600 \mathrm{t} / \mathrm{d}$ of coal while each Mark 4 unit consumes about $1000 \mathrm{t} / \mathrm{d}$. This puts total coal usage at $9000-11000 \mathrm{t} / \mathrm{d}$, nxygen demand at $65,000-95,000 \mathrm{~m}^{3 / \mathrm{h}}$ and raw gas production at $450,000 \mathrm{~m}^{3} / \mathrm{h}-600,000 \mathrm{~m}^{3} / \mathrm{h}$. These total figures depend greatly on the demand for gas by the synthesis units and the gas pipeline. The Mark 5 gasifier is designed to produce $75,000 \mathrm{~m}^{3} / \mathrm{h}$ of raw gas from $1350 \mathrm{t} / \mathrm{d}$ of coal. ${ }^{14}$

*All gas volumes in this report are normal cubic meters for which the conditions $0^{\circ} \mathrm{C}, 101.325 \mathrm{kPa}$ and dry, apply. 


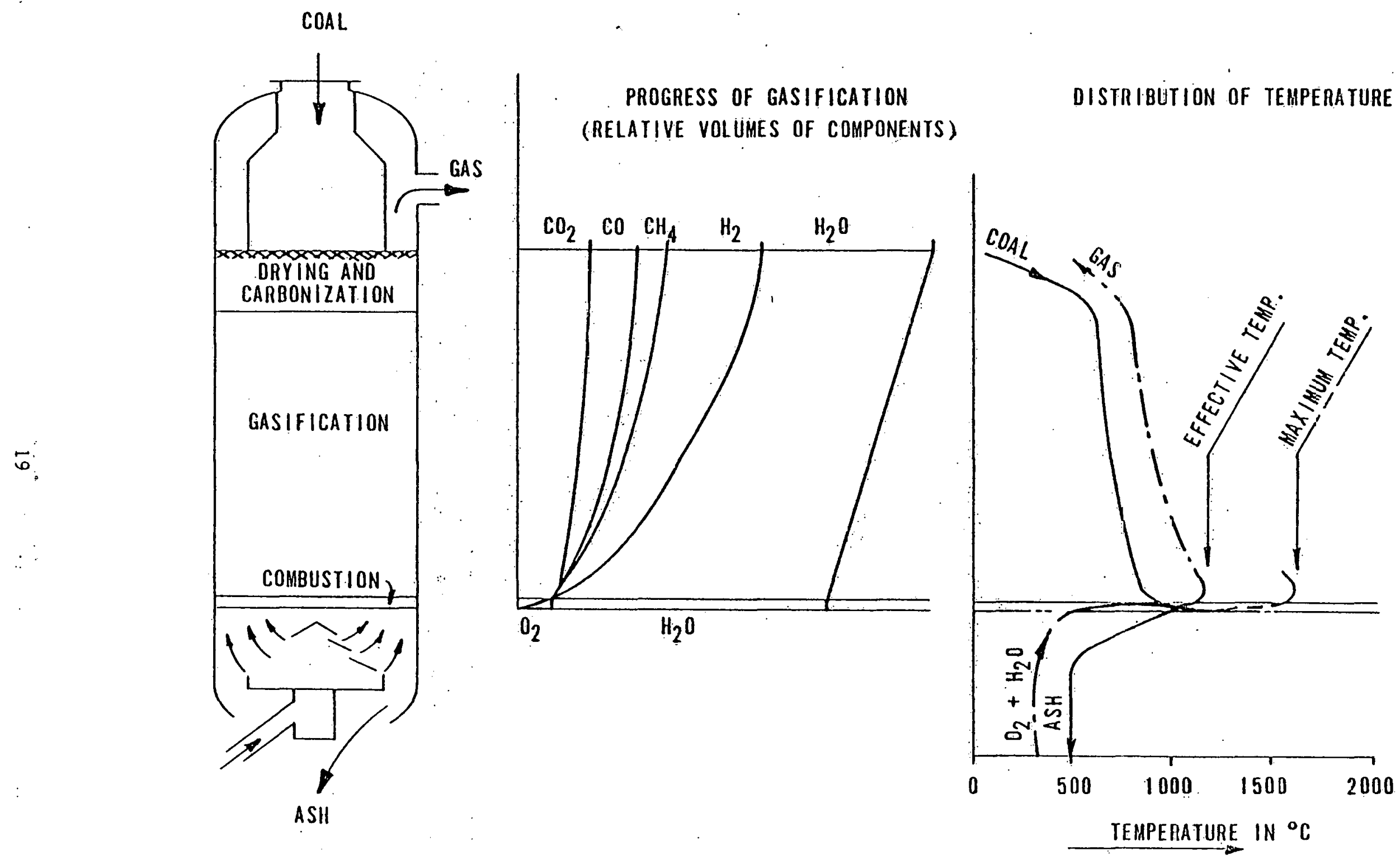

FIGURE 2.4

TEMPERATURES AND COMPOSITIONS IN A LURGI GASIFIER

REFERENCE (17) RUDOLPH 
Table 2.3 Raw Gas Compositions, Volume $\%^{20}$

\begin{tabular}{lcc}
\hline Component & Arge & Synthol \\
\hline & & \\
$\mathrm{H}_{2}$ & 39 & 40 \\
$\mathrm{CO}$ & 22 & 18 \\
$\mathrm{CO}_{2}$ & 28 & 31 \\
$\mathrm{CH}_{4}$ & 9 & 9 \\
$\mathrm{~N}_{2}$ & 1 & 1 \\
$\mathrm{H}_{2} \mathrm{~S}$ & 1 & 1 \\
\hline
\end{tabular}


Over the years, start up procedures for the gasifiers have shortened from 3 days to 12 hours. The procedure now is to fill the reactor partially with coal followed by heating with high pressure steam and ignition of the coal with air injection. When a proper fire is established, air is replaced by oxygen and the pressure is gradually increased from atmospheric lo 2.6 IPä. 11

Coal remains in the slow moving bed for about one hour. ${ }^{17}$ In the counter-current gas phase the steam and oxygen start at the bottom of the reactor vessel and rise through the ash and coal.

Near the grate, combustion of the remaining char takes place. This provides the energy for the endothermic gasification, devolatization and drying zones further up the reactor. At the top of the vessel the product raw gas exits at about $500^{\circ} \mathrm{C}$. Besides the gaseous components the product also contains tar, oil, naphtha, phenols, ammonia and traces of coal and ash dust.

The raw gas passes through a scrubber where it is washed with circulating gas liquor. This also cools the gas steam to a temperature where it is. saturated with steam. As higher boiling point tar fractions are condensed, tar in the wash water, to which the coal and ash dust adheres, increases. The steam saturated gas proceeds to the waste heat boiler where further condensation takes place because it is cooled to $160-180^{\circ} \mathrm{C}$. The waste heat boiler generates $240 \mathrm{kPa}$ steam ${ }^{2}$ which, after superheating in a coal lock gas-fired superheater, joins that in the factory low pressure network. The raw gas now enters the Arge or Synthol gas header and moves on to the appropriate Rectisol unit for purification.

Tars and oils are separated from the gas liquor in a decanting system at the tar separation plant. The oil is less dense than water while the tar's density is greater than $1.0 \mathrm{~kg} / \mathrm{L}$. These two streams are recombined and then joined by whatever residual pitch is separated from the gas liquor in the Phenosolvan plant. 
The combined stream contains virtually all the fine coal and ash that left the gasifier in the raw gas stream. Although early practice allowed this ash to be concentrated in the pitch fraction during tar distillation, more recent product requirements have dictated that it be removed. To achieve this a Funda leaf filter was installed upstream of the tar distillation columns to process the entire tar/oil/pitch stream. It is much easier to pump and filter the whole than to process the tar alone. The recommended operating procedure for the filter had to be drastically altered before adequate performance was achieved. Virtually all the problems that were encountered with the Funda filter installed at the Wilsonville, AL SRC pilot plant occurred at Sasol: blinded screens, screen tearing, gross rotational imbalances during filter cake reuluid, dind others. 21 Howcver, if the filter caparity is suitably oversized and there is enough surge capacity in tanks before and after the filter, then the product quality can be kept acceptable. The system at Sasol One can handle much more than the $200-250 \mathrm{~m}^{3} / \mathrm{d}$ of tar and oil gasification byproducts. The production rate of tar, oil and naphtha from gasification, Rectisol and Phenosolvan is $22.9 \mathrm{~L} / \mathrm{t}$ of coal (as received). 11 The Rectisol naphtha $(5.1 \mathrm{I} / \mathrm{t})^{22}$ does not go through the filter.

Distillation occurs in two parallel columns. The second was installed during the gas production expansion scheme of $1976 / 77$. Products include light and heavy naphthas, creosotes for disinfectants and wood preservatives, road tar primes for road building, coal tar fuel for furnace firing and pitch for sealing/weather proofing and fiber pipe impregnation. 23 . The light and heavy naphthas along with naphthas separated in the Rectisol gas purification units are hydrogenated over a tungsten molybdenum catalyst and refined into motor benzol for gasoline blending, and solvents for paint thinners." 
The remaining gasification byproduct is the aqueous gas liquor stream. Herein lie the tar acids (phenols, etc.) at $1800 \mathrm{ppm}$ and the ammonia at $8500 \mathrm{ppm}{ }^{13}$ The Phenosolvar plant which presently consists of four trains, recovers this material. After gravitational separation of residual tars and oil, each stream uses uormal buryl acetate ${ }^{24}$ in a countercurrent horizontal extractor to extract the phenols. 13 Live steam in a packed tower is used to strip off the butyl acetate from the gas liquor without removing much of the ammonia. Careful control of the top temperature allows this to be achieved. The rich.butyl acetate is treated in atmospheric and then vacuum distillation columns to recover the crude phenol. Table 2.4 shows the components of the crude tar acids.

The Atar subsidiary is charged with selling or further processing the crude phenol. 6

Subsequent to the separation of the butyl acetate from the gas liquor, the latter is stripped of ammonia. The ammonia vapor. in which the ammonia concentration is about $6 \%$ is routed to the ammonium sulfate plant where a conventional coke-oven-plant-type saturator carries out the production of the final product ammonium sulfate which is crystallized and sold as fertilizer. 13,23

The stripped gas liquor now contains 250 ppm phenols and only $240 \mathrm{ppm}$ ammonia. Together with other effluents from the chemical plants in the Sasolburg area and domestic sewage from the town, the gas liquor is biologically treated. The bio-treatment plant is a conventional plant consisting of primary settlement of the domestic sewerage, cooling of the treated gas liquor to about $60^{\circ} \mathrm{C}$, and flocculation of the petrochemical effluents to remove oil. The flows from these primary steps are then combined and treated on trickling filters. The purified effluent is sand-filtered to remove last traces of solids and returned to the factory where it is used in the hydraulic removal and transport of ash which 
Table 2.4 Crude Tar Acid Composition 11

$\begin{array}{lc}\text { Neutral Oil } & 1 \% \text { wt } \\ \text { Pyridine bases } & 2 \\ \text { Phenol } & 38 \\ \text { n-Cresol } & 8 \\ \text { m,p-Cresols } & 14 \\ \text { Xylenols } & 13 \\ \text { Higher boiling point tar acids } & 16 \\ \text { Pilch } & 8\end{array}$


has the advantage that the color of the effluent improves considerably by contact with the ash. Also the last traces of oil are removed by the contact with the ash to a level of below $2.5 \mathrm{ppm}$. The overflow from the ash water system goes to large daus with a retention time of approximately 12 days. In these dams further maturation takes place and they also act to even out fluctuations in purity so that a stream of constant purity flows back to the river. 11

Raw gas from the gasifiers, having been cooled to $20-25^{\circ} \mathrm{C}^{13}$ and separated from the tar, oil and gas liquor, enters one of three major Rectisol trains. The purpose of these units is to remove the carbon dioxide, hydrogen sulfide and organic sulfur so that pure gas is produced. The Rectisol process was chosen because it required. the use of only one solvent, methanol, to remove all of the unwanted material. The merit of keeping the system as simple as possible is borne out by the $97 \%$ availability of these units. Part of the non-availability is the biennial shutdown when the units have to be off line for statutory pressure vessel testing and overhaul. 11

The three Rectisol trains are not the same size. The oldest is actually three streams with a common methanol recovery system. This train was designed to produce about $125,000 \mathrm{~m}^{3} / \mathrm{h}, 13$ but with twenty-five years of debottlenecking and improved operating techniques can deliver about $165,000 \mathrm{~m}^{3} / \mathrm{h}$. The next train which was installed in 1966 can deliver about $105,000 \mathrm{~m}^{3} / \mathrm{h}$ and the most recently added train (1977) delivers about $130,000 \mathrm{~m}^{3} / \mathrm{h} .2,11,12$

The scrubbing process takes place in three stages - prewash, main wash and fine wash. In each stage methanol is used as the solvent. The prewash is to remove the last traces of aromatics 
and organic sulfure compunds. Most of the aromatics and organic sulfure compounds have already been removed during the initial cooling process in the Rectisol units. There, by heat exchange, the incoming raw gas is cooled to $-35^{\circ} \mathrm{C}$.

After the prewash the gas enters the main wash tower which is where wust of the $\mathrm{CO}_{2}$ and practically $a l 1$ the $\mathrm{H}_{2} \mathrm{~S}$ is ceñoved. The methanol used has an inlet cemperature of $-55^{\circ} \mathrm{C}$. Low pressure ammonia is evaporated in cooling coils in the tower to remove the heat of absorption of the gas and maintain the required temperature in the tower: The fine wash tower brings the $\mathrm{CO}_{2}$ level down to less than $1 \%$ and the $\mathrm{H}_{2} \mathrm{~S}$ level to less than $0.03 \mathrm{ppm}$ (Fig. 2.5 shows the historical improvement in sulfur removal ${ }^{25}$ ). Besides removal of $\mathrm{CO}_{2}$ and $\mathrm{H}_{2} \mathrm{~S}$ the pure gas leaving the facility has a very low dew point of $-55^{\circ} \mathrm{C}$ which is desirable when some of the gas is mixed into the gas pipeline for long distance delivery.

The regeneration of the methanol from all the wash stages is done by multistage depressurization. The gas that is released during first stage depressurization (expansion gas) contains sufficient $\mathrm{H}_{2}$, $\mathrm{CO}$ and $\mathrm{CH}_{4}$ along with the $\mathrm{CO}_{2}$ that is useful as a low quality $\left(10 \mathrm{MJ} / \mathrm{m}^{3}\right)$ fuel gas and is used in the factory fuel gas system. There is no problem about getting this gas into the fuel gas system because the pressure at its source in the Rectisol plant is $1.0-1.4 \mathrm{MPa}$.

The remainder of the expansion gas which gets released into a low pressure header, is where the $\mathrm{CO}_{2}$ (98.5\%) and $\mathrm{H}_{2} \mathrm{~S}(1.5 \%)$ leaves the Rectisol area. Up until 1978 this low pressure expansion gas was vented to atmosphere with the boiler flue gases four, through the $75 \mathrm{~m}$ high power plant stacks. Offensive though the smell of the $\mathrm{H}_{2} \mathrm{~S}$ could be, even at this dilute level, the prevailing winds kept the plume away from the residential areas most of the time. 


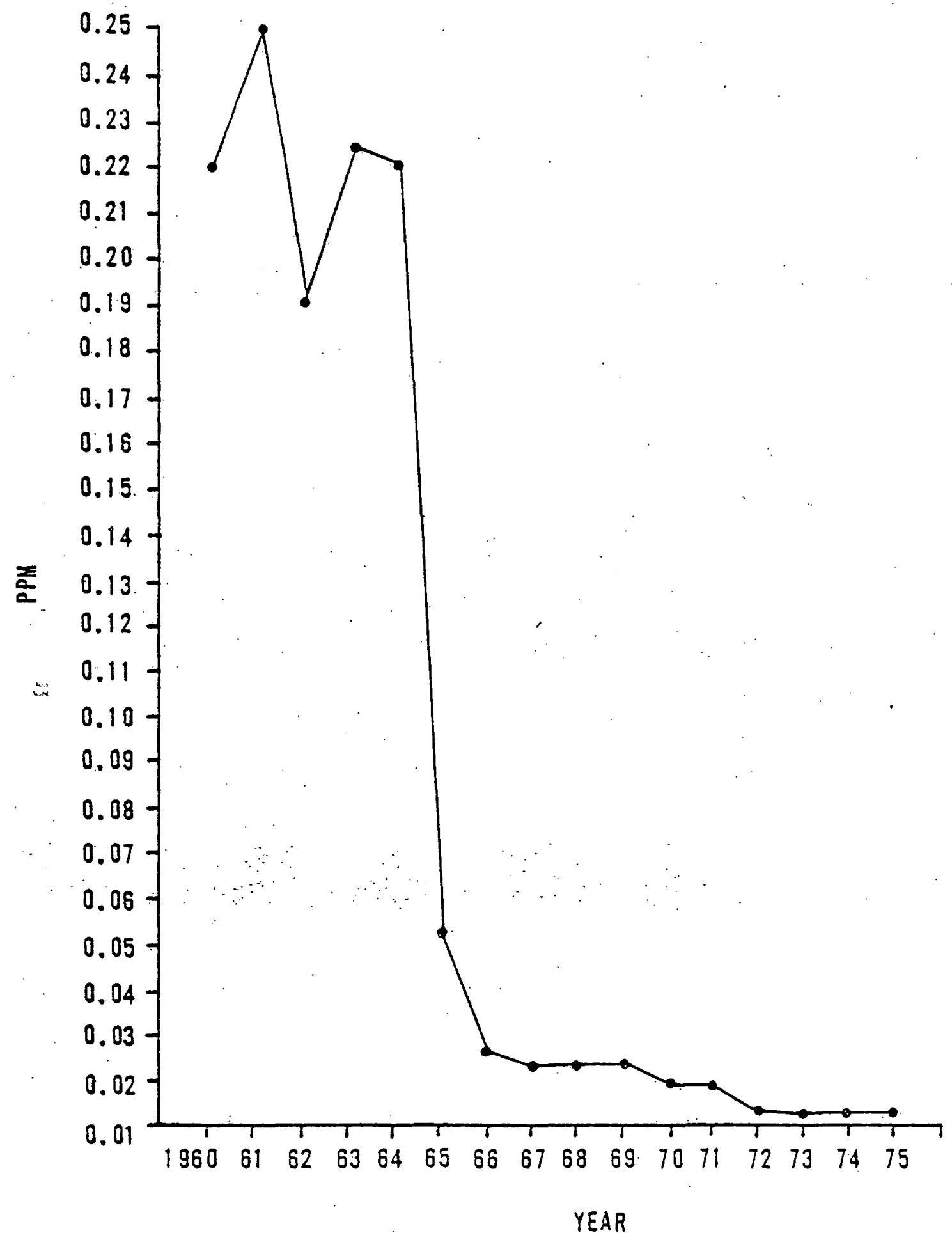

FIGURE 2:5.

PURE GAS SULFUR LEVELS DURING

SASOL ONE OPERATING HISTORY

REFERENCES $(11,25)$ HOOGENDOORN 
As part of the gas production expansion scheme of the mid-1970's Sasol One installed a Stretford unit to lower the $\mathrm{H}_{2} \mathrm{~S}$ levels in the expansion gas to $50 \mathrm{ppm}$ and recover elemental sulfur for sale. 26,34 In order to handle the 110,000-140,000 $\mathrm{m}_{\mathrm{n}}^{3 / \mathrm{h}}$ of expansion gas, twin towers $85 \mathrm{~m}$ tall and $8 \mathrm{~m}$ in diameter packed with wood were installed. These, together with tanks to oxidize and decant the solvent, allow the $\mathrm{H}_{2} \mathrm{~S}$ to be selectively removed from the gas stream and oxidized to elemental sulfur. Material balances indicate that some $50 \mathrm{t} / \mathrm{d}$ of sulfur should be recovered. I'he cleaned $\mathrm{CO}_{2}$ is vented to atmosphere from the top of these towers. Careful conditioning of the packing in the towers is necessary.

Methanol recovery at the Rectisol units differs depending on its use. That from the cooler groups at the front end of the plant and the prewash tower is depressurized and has water added to bring about a separation between watery methanol and Rectisol naphtha. The naphtha is pumped away to the naphtha hydrogeneration area where it joins naphtha from tar distillation. The remaining methanol is stripped to remove traces of naphtha, rectified to remove the water and cooled before being pumped to the main wash tower. ${ }^{13}$ Methanol from the main and fine wash towers is regenerated by depressurization before being returned to those respective towers. Total methanol usage is about $10-20 \mathrm{~m}^{3} /$ day for cleaning up all the raw gas.

Rectisol utility consumption averages $35.7 \mathrm{kWh}$ of electricity and $79.2 \mathrm{~kg}$ of steam per $1000 \mathrm{~m}^{3}$ of pure gas. The main energy consumption in the plant is for driving the methanol circulation pumps and the compressors for the ammonia refrigeration systems. 11

The pure gas that is the product of the Rectisol areas is mostly destined for one of the synthesis areas. However, some of it may be fed to the methane reformers. Far less is sent to these reformers today than was the case when the facility first came 
on line. Up until the early 1970 's it was the practice to send only gas that had been reformed (methane level reduced) to the Synthol reactors. With more and more of the Synthol and Arge tail gases being sent to be blended into the medium energy $\left(20 \mathrm{MJ} / \mathrm{m}_{\mathrm{n}}{ }^{3}\right.$ ) industrial gas instead of being reformed, the methane concentration in the reformer feed gas dropped. This, in turn, led to decreasing thermal efficiency at the reformers. At the same time the overall Sasol One system thermal efficiency was increasing because less gas was being reformed as more tail gas was sold to Gascor for distribution to industrial users.

The steam-methane reforming reaction is

$$
\mathrm{CH}_{4}+\mathrm{H}_{2} \mathrm{O} \rightarrow 3 \mathrm{H}_{2}+\mathrm{CO}
$$

and one molecule of methane yields four molecules of synthesis gas. Large quantities of energy are needed to achieve the required temperatures $\left(900+{ }^{\circ} \mathrm{C}\right)$ in the reformer reactor and so fuel must be consumed. In a partial oxidation reformer of the type that was installed at Sasol One, some of the feed material $\left(\mathrm{CH}_{4}, \mathrm{H}_{2}\right.$, or CO) must be burned in the reactor to provide the energy. Thus, in a pure methane feed only about 3.1 molecules of desired product would result for every one $\mathrm{CH}_{4}$ that starts. With more dilute. methane concentrations the mark up diminishes linearly with methane concentration. By definition mark up is the volume of product (reformed) gas out divided by the volume of feed gas in to the reformer. It is possible at low methane concentrations ( $<5 \%)$ to have a net reduction in gas volume, i.e., mark up $<1.0$.

Oxygen consumption per unit volume of feed increases with methane content of the feed. However, the weight ratio of oxygen/hydrocarbons remains almost constant. Steam also has to be added to the system and a steam/hydrocarbons weight ratio of about 2.0 is maintained. 13 
At Sasol One there are five reformers but at present only three are able to be used. Originally the gas reforming plant was divided into two yards with two reformers in each and a common spare. ${ }^{13}$ After Sasol's most serious acciden,t in April 1975, destroyed most of the equipment in one yard, the decision was made to rebuild only the least damaged yard with three reformers. Operating policy endeavored to keep at least one reformer on line at all times even if this is not the most efficient mode of operation. Production management believes this is the safest alternative. The other option would be to run the reformers only when there was tail gas from Arge or Synthol to be reformed. However, it had been during the transition from equipment on line to plant shut down that poor communications had led to uxyyeu being present in a hydrocarbon atmosphere downstream of the reactor. The resulting explosion in a post-cooler group knock out drum demolished the nearby equipment and control room with a toll of seven dead. Ironically, the blast wall that was supposed to protect the rest of the plant in the event of an explosion in a performed admirably, leaving the reformers virtually unscathed.

By heat exchange with the hot reformed gas product the feed gas is beated from about $35^{\circ} \mathrm{C}$ to $150^{\circ} \mathrm{C} .{ }^{13}$ At this point the feed is jointed by the $3.1 \mathrm{MPa}$ steam generated in the unit's quench boiler. The mixture cools slightly but further heat exchange with the product streams raises the steam/gas temperature to $650^{\circ} \mathrm{C}$. Partial by-passing of the heat exchanger allows for temperature control. The mixture is then introduced at the top of the reactor through mix-nozzles. Oxygen, with some sweep steam to prevent burn back, is also added here. The stainless steel nozzles are high pressure water cooled. The reactor is made of stainless steel and is refractory lined and water jacketed. 13 
Although the lower portion of the reactor is filled with aickel catalyst, ${ }^{7}$ the upper portion is empty. It is in this empty portion that the partial oxidation occurs that provides the energy for the reforming reaction which occurs mainly with in the catalyst bed. The reaction temperature is about $1000^{\circ} \mathrm{C} .^{7}$.

The reformed gas has a composition such as that given in Table 2.5. ${ }^{13}$ As can be seen the $\mathrm{H}_{2} / \mathrm{CO}$ ratio is 2.77 which is on the high side stoichiometrically for hydrocarbon synthesis but is good for lessening carbon formation on the Synthol catalyst: ${ }^{27}$ After passing through the quench boiler, heat exchange with the feed gas, a waste heat boiler and a scrubber, the reformed gas leaves for the Synthol area. 
Table 2.5 Reformed Gas Composition ${ }^{13}$

\begin{tabular}{cc}
\hline $\mathrm{H}_{2}$ & $61.6 \% \cdot \mathrm{vol}$ \\
$\mathrm{N}_{2}$ & 3.7 \\
$\mathrm{CO}$ & 22.2 \\
$\mathrm{CO}_{2}$ & 7.2 \\
$\mathrm{CH}_{4}$ & 4.7 \\
$\mathrm{H}_{2} \mathrm{O}$ & 0.6
\end{tabular}


2.4 SYNTHOL SYNTHESIS AND PRODUCT REFINING

Of all the untried and untested technology that Sasol put into the original Sasol One facility the Synthol reactors proved to be the most intractable. The first liquid products emerged in August 1955 and it took about five years before the operating staff felt confortable with the reactors. ${ }^{1}$

The physical appearance of these reactors is very distinctive (Figure 2.6$)^{19}$ and in any photograph of the Sasol one facility the goose necks at the top of the three reactors can be seen above most of the other equipment.

A reactor has a horizontal inlet pipe of $1.05 \mathrm{~m}$ in diameter. ${ }^{13}$ All the gas enters the reactor through this pipe and immediately before it curves up to the vertical reaction section, the catalyst falls into the gas from the standpipe through the slide valves. Although the gas has been preheated to $160^{\circ} \mathrm{C}{ }^{13}$ the catalyst, which is circulating at the rate of some $8000 \mathrm{t} / \mathrm{h}^{19}$ in each reactor, quickly brings the entering combined feed to $315^{\circ} \mathrm{C}$. The preheater is needed to adjust the inlet temperature, particularly during startup. The combined feed consists of a recycle gas stream at a fairly constant $200,000-210,000 \mathrm{~m}^{3} \cdot / \mathrm{h}$ and a pure gas/reformed gas fresh feed that may vary from $65,000-95,000 \mathrm{~m}^{3} / \mathrm{h}$ in the $A$ and $B$ reactors or $70,000-125,000 \mathrm{~m}^{3} / \mathrm{h}$ in the $C$ reactor. The recycle and fresh feed streams each have their own compressor. The reactor pressure is $2.3-2.4$ Mpa .

By the time that the gas mixture and catalyst have reached the vertical reactor vessel the reaction is well under way. Because synthesis reactions are exothermic the heat of reaction must be dissipated or else the hydrocarbon molecules will crack to carbon which will be deposited on the catalyst particles. To prevent 


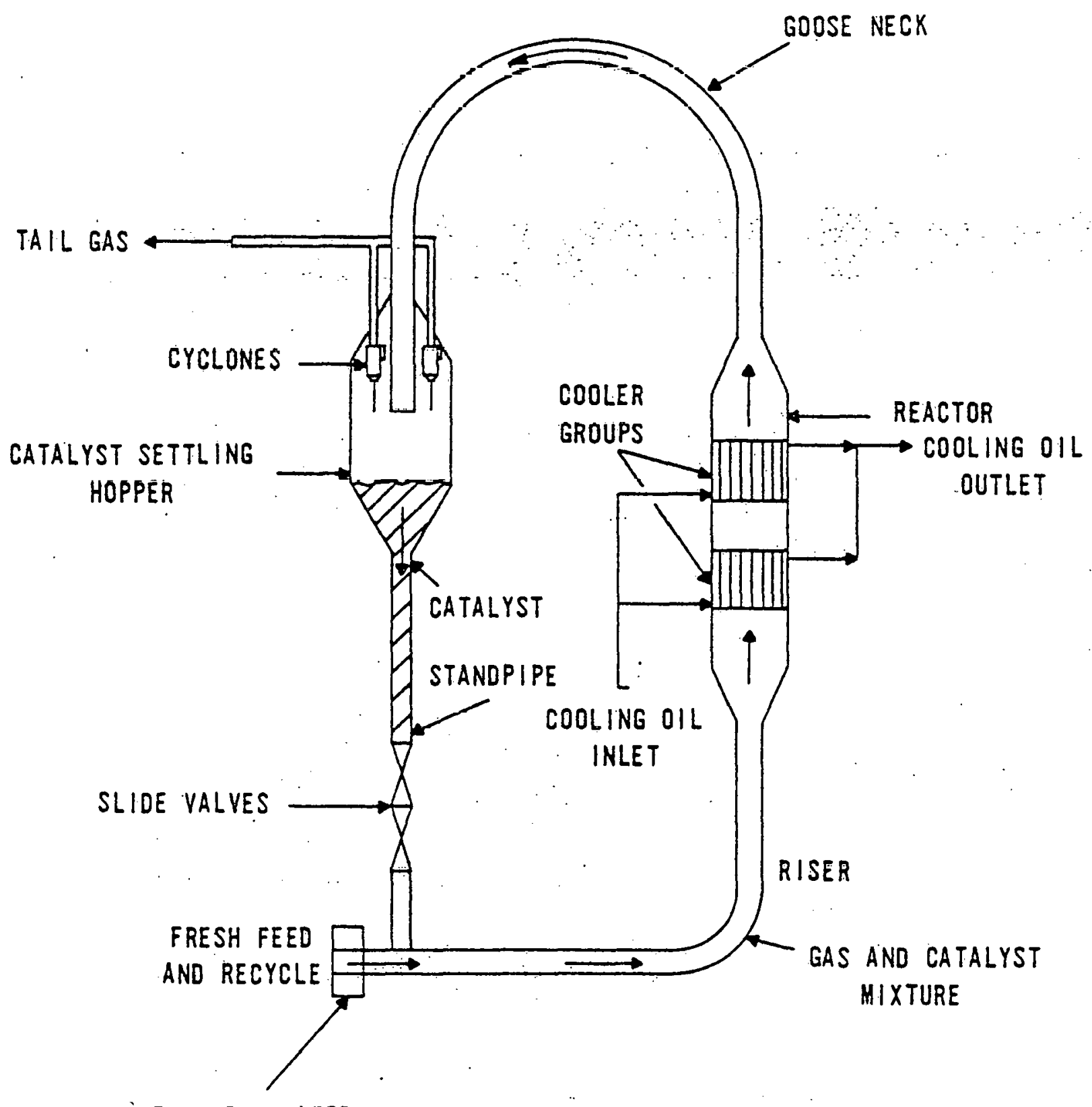

FEED PREHEATER

FIGURE 2.6

SYNTHOL REACTOR

REFERENCE (19) ROBERTS 
this two intercoolers are placed in the reactor sections. In the $A$ and $B$ units these are shell and tube heat exchangers with the gas and catalyst passing through the vertical tubes and heat transfer oil being pumped around the shell side. The oil goes to a waste heat boiler where $1.2 \mathrm{MPa}$ steam is raised. ${ }^{28}$ It was noted that if the catalyst particles became sticky because the heavier hydrocarbons that were synthesized started condensing, then the catalyst would adhere to any surface. I By nature of the gas flow through these intercoolers is unstable. Dense phase plugs tend to form in the tubes and if these settle and cool, then the catalyst would block the tubes. If this continued for long enough then the coolers became too blocked to allow reasonable flows through the reactor with excessive pressure drop. The reactor would. then be shut down for a cleaning and a catalyst change. 29

In order to overcome the blockage problem in the intercoolers the $C$ reactor were modified. The shell and tube exchangers were removed. In their place serpentine coils were installed. $29 ; 30$ Here many vertical tubes were connected to adjacent neighbors alternately at the top and then the bottion to form a path for the oil that was a series of upward then downward passes. Heat transfer was found to be as good as before and it was even possible to increase the loading on the reactor. Extra metal caps at the lower portions of the bends helped prevent erosion by the catalyst. Because the gas/catalyst mixture was on the outside of the tubes, there was no: further blockage problem.

By varying the oil flow through the coolers the top temperature in the reactor could be maintained at $340^{\circ} \mathrm{C}$. This temperature was usually achieved in the goose neck at the top of the reactor and the catalyst settling hopper. ${ }^{20}$ At this temperature level the water gas shift reaction does play a part in determining the composition of the gas as it leaves the reactor. 
From photographs of these reactors it can be seen that the goose neck is about $1.05 \mathrm{~m}$ in diameter and the reaction section about $2.25 \mathrm{~m}$ in diameter. The total height of the reactor is $36 \mathrm{~m} .13$ There. is refractory material in the reactor riser and goose neck to stop the catalyst abrading bare metal.

In the catalyst settling hopper there are four cyclones which disengage the catalyst from the gas. The gas leaves the reactor through these cyclones carrying with it some of the very fine particles of catalyst. The remaining catalyst is returned to the catalyst. inventory in the settling hopper via a valved dip leg. The catalyst, which retains most of its heat energy, moves down the standpipe, through the two slide valves and into the gas coming into the reactor where this energy is used to heat up the gas. 13

The progress of the catalyst particles through the standpipe is occasionally halted by bridging. ${ }^{1,29}$ Here the catalyst compacts to form a natural bridge across the pipe which will not allow any further catalyst through. Testing has been done at Sasol One to determine the cause(s) of this bridging. The results have been applied to the design of the Synthol reactors, particularly the catalyst settling hopper, for Sasol Two. 29

Catalyst for the Synthol reactors is manufactured on site. Mill scale from a nearby steelworks provides the iron base. ${ }^{20}$ Having ground the material to -16 mesh, promoters are added in very small percentages, in carefully metered quantities. These components are then fused together using an open arc electric furnace. After leaving the furnace at about $1500^{\circ} \mathrm{C}$ the catalyst solidifies as it cools. It is then crushed to $-16 \mathrm{~mm}$ and then ground to about 200 mesh. The final stage in catalyst preparation is the chemical reduction using hydrogen which takes about 2 days. The catalyst is stored in an oxygen free environment. 13 
About 120-130 tonnes of catalyst is estimated to be required to load a reactor. ${ }^{31}$ As has been pointed out ${ }^{27}$.carbon formation through the Boudouard reaction $\left(2 \mathrm{CO} \rightarrow \mathrm{CO}_{2}+\mathrm{C}\right)$ is known to occur rapidly at typical synthesis temperatures of $325^{\circ} \mathrm{C}$. Laboratory testing 27 revealed a good correlation between carbon. deposition rate and $\mathrm{p}_{\mathrm{CO}} / \mathrm{p}^{2} \mathrm{H}_{2}$ where $\mathrm{p}_{\mathrm{CO}}, \mathrm{p}_{\mathrm{H}_{2}}$ are the partial pressures of carbon monoxide and hydrogen. Keeping the $\mathrm{H}_{2} / \mathrm{CO}$ ratio higher than the stoichiometric requirement of about 2.1 would tend to lessen the formation of carbon on the catalyst.

A batch of catalyst is used for an average of 40-44 stream days. 30 However, much of the active catalyst is lost by attrition as it divides up into smaller particles and escapes through the cyclones. Eventually the reactior ceases to achieve the required levels of conversion and yield and is shut down for catalyst change.

A recent innovation has been the modification of $C$ reactor to allow periodic catalyst removal and addition. In a test started in July 1979, this was done on six occasions during an 89 day period. 30 The reactor was actually on line for 1831 hours which is a considerable improvement over previous one-shot catalyst loads.

Over the lifetime of the Sasol One facility the performance of all the process units has improved to well over the original design levels. The Synthol reactors are no exception. Figures 2.7 and 2.8 indicate how the $\mathrm{CO}$ and $\mathrm{CO}_{2}$ conversion improved in the 1969-1972 period and improvement of useful product yield between 1963-1973. Some explanation may be needed. Sasol considers that all carbon in the fresh feed to the Synthol that is not already bound up in hydrocarbons (which are inerts in the $F-T$ reaction), is available for conversion into hydrocarbons and oxygenates. Conversion then, is the percentage of these carbon atoms that did indeed find their way into these products in the 


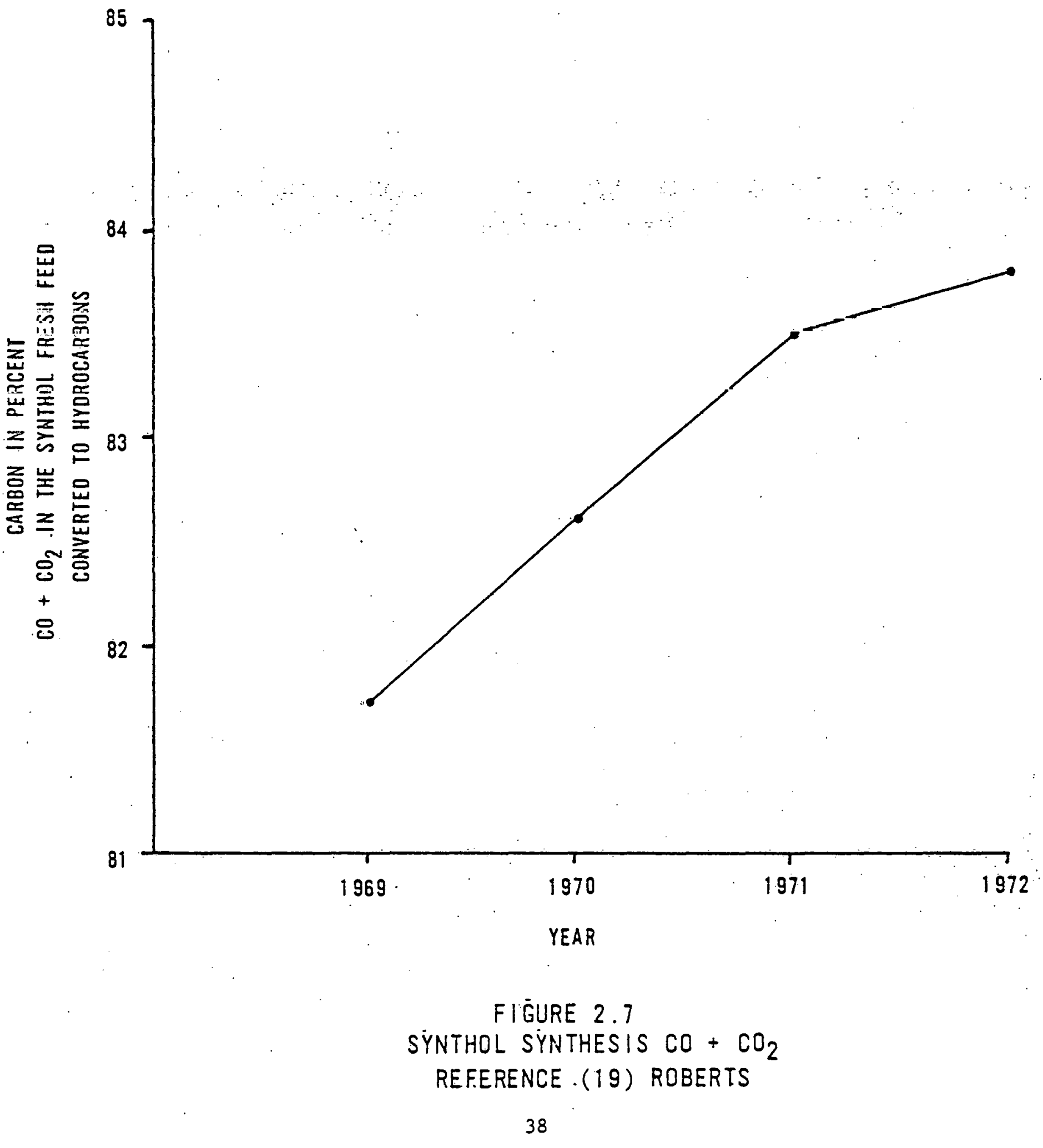




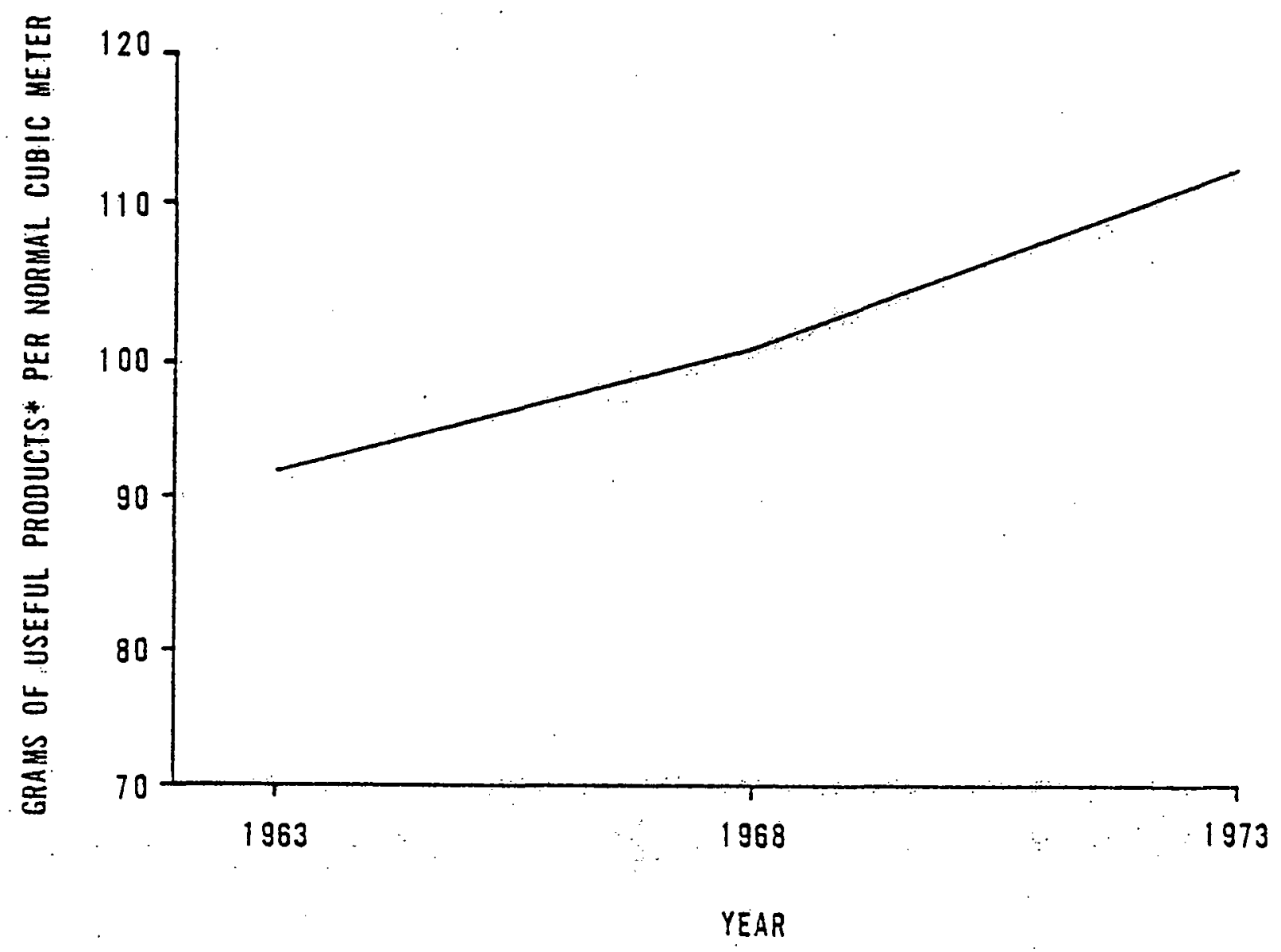

* USEFUl products include all hyorocarbons and oXygenates except METHANE, ETHANE, ETHYLENE, AND ORGANIC ACIDS

FIGURE 2.8

SYNTHOL SYNTHESIS USEFUL PRODUCT

REFERENCE (19) ROBERTS 
tail gas and liquid streams. Useful products are considered to be all hydrocarbons from $\mathrm{C}_{3}$ up plus the non-acid chemicals. Methane, ethane, ethylene and organic acids are not deemed to be useful. Obviously the sale of industrial medium energy gas gives a use for the methane, ethane and ethylene as well as the unconverted $\mathrm{H}_{2}$ and $\mathrm{CO}$ but the definition was established before Gascor came into being.

All the products of the Synthol synthesis leave the reactor as vapor. This stream enters a scrubber tower ${ }^{13}$ where the gas is cooled and the heavy oil and entrained catalyst are removed. The scrubbing medium is previously produced heavy oil. Eventually the catalyst that is captured by this heavy oil is concentrated by decanting off the heavy oil after settling. The decanted oil is moved on to the refinery section for further processing while the catalyst "gunk" is disposed of. By keeping the temperature at the top of the scrubber tower at about $150^{\circ} \mathrm{C}$, the water remains vaporized and leaves with the other gaseous products in the overhead stream.

This overhead stream is cooled to about $40^{\circ} \mathrm{C}$ by heat exchange with boiler feed water and then cooling water. ${ }^{13}$ The remaining uncondensed gas is demisted and a large portion of it is returned by the recycle compressors to the reactor inlet. The rest of the gas proceeds to an absorber column where lean oil absorbs $C_{3}$ and $C_{4}$ material. The liquid from the condenser separates in a separator drum, into an oil fraction and a water fraction containing the non-acid chemicals and fatty acids produced in the reactor. The oil stream is sent to the refinery for further processing into gasoline, diesel fuel, etc. and the water goes to the chemical recovery section for the recovery of alcohols and ketones, hydrogenation of the aldehydes, and the disposal of the acids. 
The selectivities exhibited by the Synthol reactors is given in Table 2.6 for various times during the run. The most obvious trends are that the light hydrocarbon gases $\left(C_{1}-C_{4}\right)$ are favored more and more as the catalyst ages while the light oil and decanted oil, from which the transportation fuels are derived, are less readily produced at the end of the run. The light oil production is one criterion that decides whether the reactor should remain in operation. Periodic catalyst removal and addition should definitely inhibit these trends, The ASTM distillations for the light oil and decanted oil are given in Figure $2.9^{20}$ with the carbon atom distribution in Table $2.7^{20}$ while the composition of the non-acid chemicals and acids is given in Table $2.8 .^{20}$

The further refining of Synthol raw products into saleable products uses mostly distillation to achieve the desired results. $C_{3} / C_{4}$ material is routed to a catalytic polymerization unit when the unsaturated propenes and butenes are polymerized into cat-poly gasoline. This is a slightly denser gasoline than is obtained from the light oil. It is also mono-olefinic. Propane and butane that are separated from the cat-poly gasoline are sent to the LPG blending equipment in the tank farm area. The Synthol $\mathrm{C}_{3} / \mathrm{C}_{4}$ work up system also processes the same stream from the Arge area.

The light oil fraction from the synthesis area is fed to clay treaters. At the inlet, the temperature of this oil has been raised to about $450^{\circ} \mathrm{C}$. It passes through a bed of silica-alumina catalyst which is isomerizes the hydrocarbons - and thereby improves the octane rating - and removes harmful acids and other oxygenates. The stream is then distilled to make gasoline, diesel fuel and some waxy, heavy oil. Heavy oils are not affected by the clay treater reactions so the decanted oil joins the light oil only for the final distillation. 13 
Table 2.6. Synthol Selectivities:

Commercial Results $12 ; 20$

\begin{tabular}{|c|c|c|c|}
\hline & $\begin{array}{c}\text { Start } \\
(\text { Day } 0-5)\end{array}$ & $\begin{array}{c}\text { End } \\
(\text { Day 35+) }\end{array}$ & Average \\
\hline $\mathrm{CH}_{4}$ & 7 & 13 & 10 \\
\hline $\mathrm{C}_{2} \mathrm{H}_{4}$ & 4 & 3 & 4 \\
\hline $\mathrm{C}_{2} \mathrm{H}_{6}$ & 3 & 9 & 6 \\
\hline $\mathrm{C}_{3} \mathrm{H}_{6}$ & $10 \quad \because$ & $\because \quad 13: \because$ & 12 \\
\hline $\mathrm{C}_{3} \mathrm{H}_{8}$ & 1 & $\because 3$ & 2 \\
\hline $\mathrm{C}_{4} \mathrm{H}_{8}$ & 7 & 9 & 8 \\
\hline $\mathrm{C}_{4} \mathrm{H}_{10}$ & 1 & 2 & 1 \\
\hline$c_{5}+$ & 6 & 9 & 8 \\
\hline 1.0 & 40 & 30 & 35 \\
\hline d.o. & 14 & 2 & 7 \\
\hline n.a.c. & 6 & 6 & 6 \\
\hline acids & 1 & 1 & 1 \\
\hline
\end{tabular}

Selectivity is the percentage of C-atoms in the carbon monoxide and carbon dioxide in the fresh feed that are converted and end up in these products.

$1.0=$ light oil, boiling point range $50-290^{\circ} \mathrm{C}$

d.o. = decanted oil, boiling point range $160-490^{\circ} \mathrm{C}$ See Figure 2.9

n.a.c. = non acid chemicals

acids = water soluble acids 


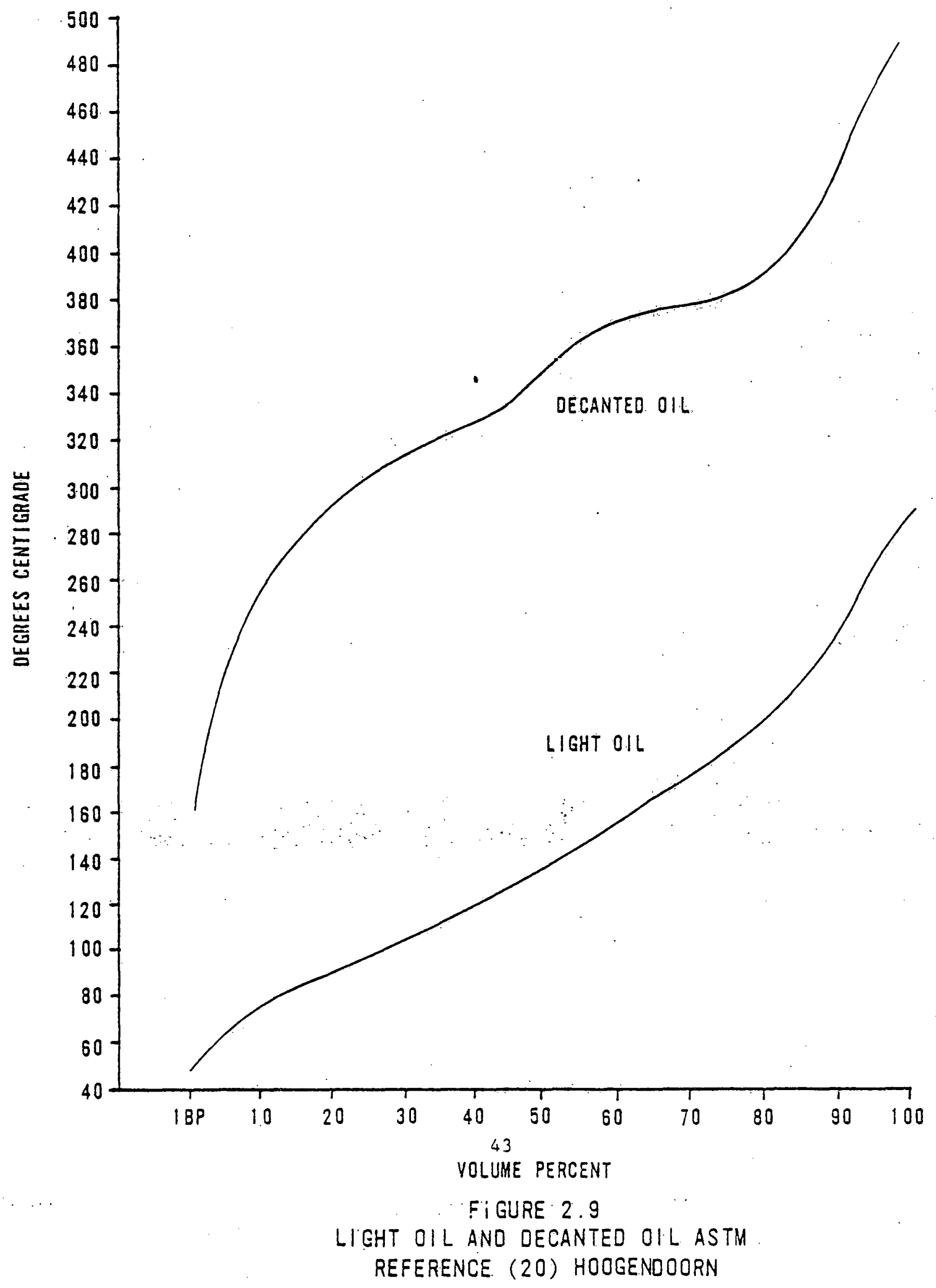


Table 2.7. Carbon Atom Distribution for

Synthol Light $0 i l$ and Decanted $\mathrm{Oil}^{20}$

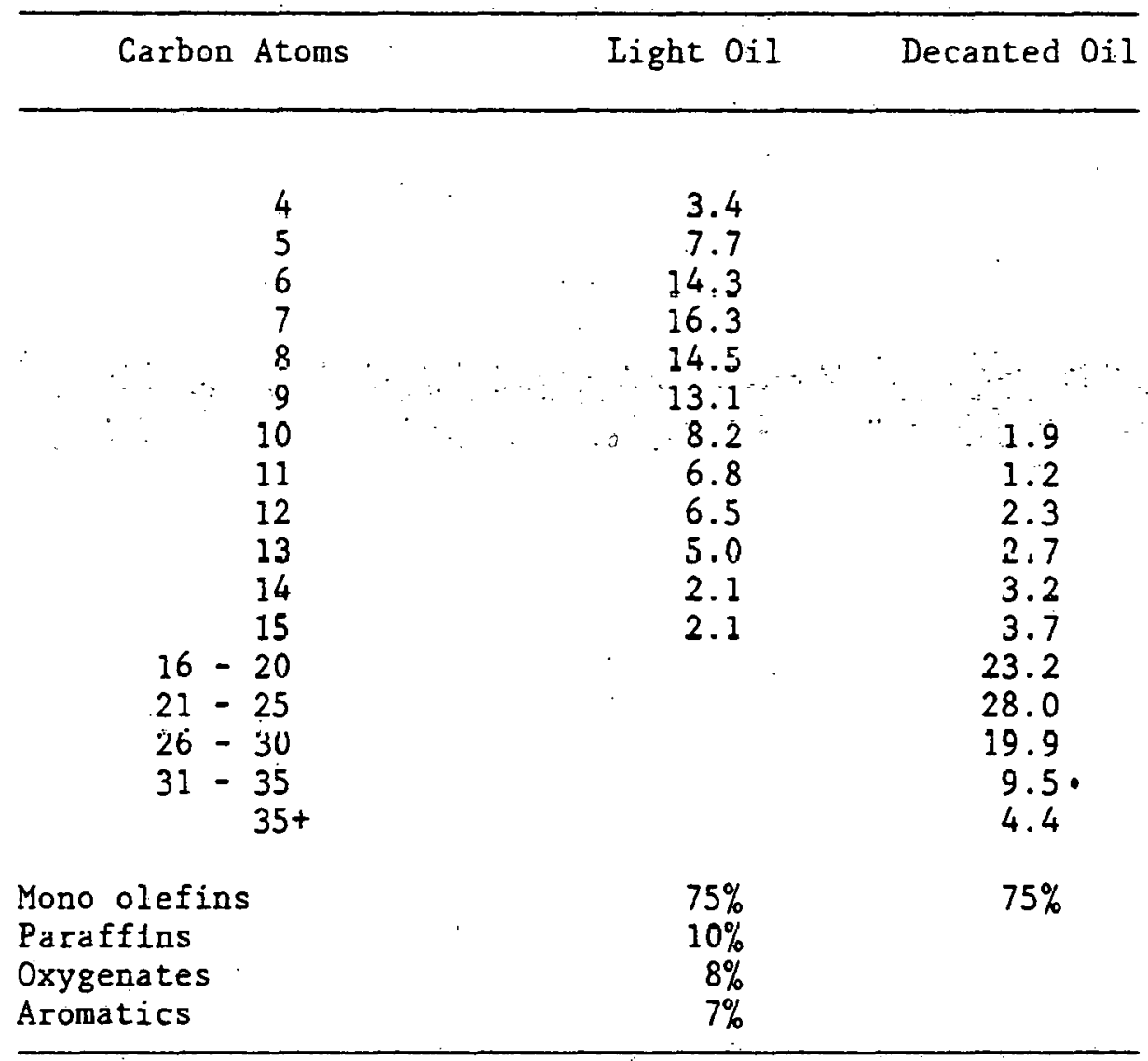


Table 2.8. Composition of Non-Acid Chemicals and Organic Acids

\begin{tabular}{lr}
\hline Non Acid Chemicals & Wt \% \\
\hline Acetaldehyde & 3.0 \\
Propionaldehyde & 1.0 \\
Butyraldehyde & 0.6 \\
Acetone & 10.6 \\
MEK & 3.0 \\
EEK-MPK & 0.8 \\
n-Butylketone & 0.2 \\
Methanol & 1.4 \\
Ethanol & 55.6 \\
i-Propanol & 3.0 \\
n-Propanol & 12.8 \\
2-Butanol & 0.8 \\
i-Butanol & 4.2 \\
n-Butanol & 4.2 \\
2-Pentanol & 0.1 \\
n-Pentanol & 1.2 \\
C6 + alcọols & 0.6 \\
\hline
\end{tabular}

\begin{tabular}{lr}
\hline \multicolumn{1}{c}{ Acids } & Wt $\%$ \\
\hline & \\
\hline & 70.0 \\
Pcetic acid & 16.0 \\
Butyric acid & 9.0 \\
Valeric acid and higher & 5.0 \\
\hline
\end{tabular}


The aqueous streams from the Arge and Synthol syntheses are processed together. The majority of unit operations performed are distillations. The first stage of the recovery of these chemicals involves separating the water from the alcohols, ketones, aldehydes and acids. In the stainless steel lined tower the water and acids are separated from the non-acid chemicals. The water/acid stream is neutralized with alkali before disposal. In the refining of non-acid chemicals, the aldehydes are stripped off first, hydrogenated and recycled to the chemical recovery area. Mixed ketones are recovered from the next tower. Finally methanol and ethanol are recovered. The mixed ketones and the heavy alcohols are separated into more refined products by batch distillation in the same tower at different times.

The absorber overhead product is the Synthol tail gac. It constitutes about $30-35 \%$ by volume of the fresh feed that entered the reactors. Its approximate composition is given in Table 2.9. Most of the methane in the tail gas was in the feed and passed through the reactors as an inert. Its proportion is so much higher because the overall volume of gas had decreased. The same can be said for the nitrogen. The concentration of $\mathrm{CO}$ is very low while $\mathrm{CO}_{2}$ is moderate indicating that the water gas shift reaction favored the $\mathrm{H}_{2}$ and $\mathrm{CO}_{2}$ side. At this point the tail gas is at about $1.8 \mathrm{MPa}$ but with compression it is a good feed material for (1) ammonia synthesis where the $\mathrm{H}_{2}$ is required, (2) reformer feed because the methane after high pressure water $\mathrm{CO}_{2}$ removal will be about $40 \%$, or (3) gas blending because it has a energy content of $22-26 \mathrm{MJ} / \mathrm{m}_{\mathrm{n}}{ }^{3}$. All of these uses are in fact pursued. 
Table 2.9. Synthol Tail Gas Composition 11

\begin{tabular}{lc}
\hline $\mathrm{H}_{2}$ & $45 \%$ vol \\
$\mathrm{N}_{2}$ & $4 \%$ \\
$\mathrm{CO}$ & $2 \%$ \\
$\mathrm{CO}_{2}$ & $12 \%$ \\
$\mathrm{CH}_{4}$ & $35 \%$ \\
$\mathrm{C}_{2}$ & $2 \%$ \\
\hline
\end{tabular}


Given the unknowns of the time, the choice of the five Arge reactors for Sasol One provided some needed security. Admittedly the reactors were bigger than those that had been used at Holten in Germany and they used iron based catalysts, ${ }^{1}$ but the process had worked in large scale applirations.

Each reactor (Figure $2.10^{28}$ ) was $12.8 \mathrm{~m}$ long and has a diameter of $2: 95 \mathrm{~m}$. A reactor contains a vertical tube bundle of 2052, 2 inch diameter tubes which are partly filled with catalyst pellets. $^{13}$ The catalyst charge of $40 \mathrm{~m}^{3} /$ reactor is supported on a grate position just below the tubes. On the shell side of the tube bundle eteam is generated by boiling water to remove the heat of reaction. The steam pressure in the shell depends on the temperature at which the reactor is being operated but the steam goeo to a 17 bar steam network. 28

The catalyst manufacturing history parallels that for the Synthol system. Originally the catalyst was bought from a source in Germany. Later a plant was built at Sasol One to manufacture it. Iron swarf is the raw material. It is precipitated catalyst with alkali metals used as the promoters. It has been estimated ${ }^{32}$ that this is a standard catalyst with Fe:Cu: $\mathrm{K}_{2} 0: \mathrm{SiO}_{2}=100: 5: 5: 25$. and that the average carbon number of the product can be decreased by decreasing the $\mathrm{K}_{2} \mathrm{O}$ and $\mathrm{SiO}_{2}$ levels. The catalyst can be used for over 200 days but it has been found that the quality of the wax deteriorates after about 100 days of operation. The yield of wax also drops with increasing catalyst age but can be partially offset by increasing the temperature in stages from $220^{\circ} \mathrm{C}$ at the start of the run until at run's end it is about $245^{\circ} \mathrm{C}$. As was is a very profitable product for Sasol the reactor run length has been optimized around its production. Reactors are brought off line for catalyst change after 70-100 days. 


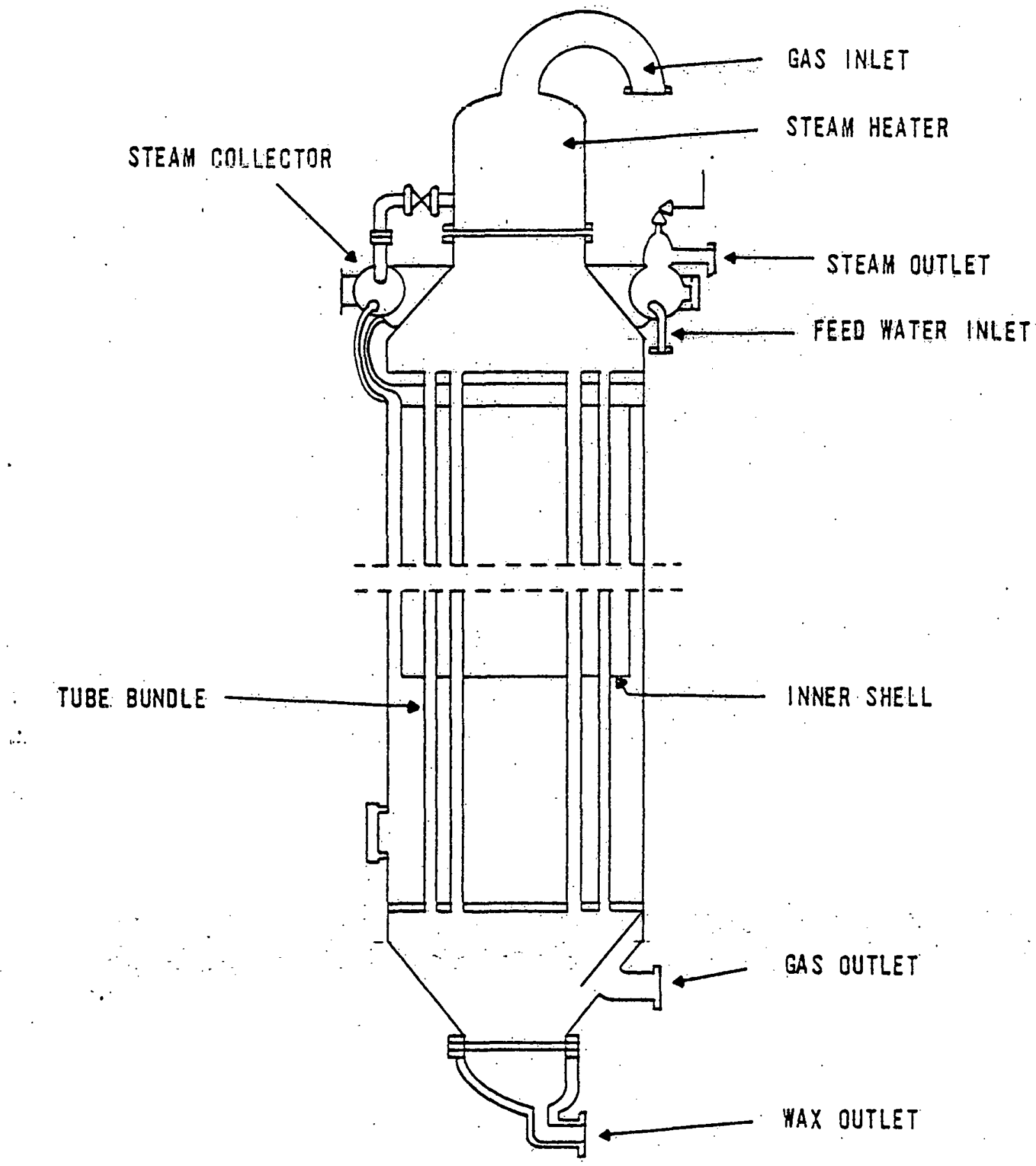

FIG̈URE 2.10

ARḠE REACTOR

REFERENCE (28) CRANJ.É 
The pressure in the reactor is about $2.5 \mathrm{MPa}$. Pure gas is boosted to this pressure along with the recycled tail gas by a single compressor per reactor. ${ }^{13}$ As this compressor operates at a fairly constant flow rate, a change in the fresh feed to the reactor (normally $20,000-28,000 \mathrm{~m}^{3} / \mathrm{h}$ ) ${ }^{32}$ brings a complementary change in the recycle flow to keep the combined feed constant. Thus, the recycle ratio can vary from 1.5-2.5 during reactor turn down from maximum to minimum load.

One of the advantages of the Arge reactors is their quick start up and shut-down. Much use is made of this to absorb shocks in the Sasol One gas circuit such as a change in the availability of pure gas, a change in the demand of medium energy industrial gas or failure of some equipment elsewhere in the gas circuit. They can be brought on line in a matter of an hour or two whereas Synthol reactors, with their higher operating temperatures and large quantity of catalyst, will need about 12 hours to come on line.

The conversion that is obtained in an Arge reactor is about $65 \%$ of the $\mathrm{H}_{2}$ and $\mathrm{CO}$ in the fresh feed. ${ }^{2}$ The basis for measuring conversion in the Arge and Synthol units is different because Arge is fed only pure gas that is essentially devoid of $\mathrm{CO}_{2}$ and it operates at a temperature which is low enough for the water gas shift reaction to play a much diminished role.

Table 2.10 compares the Arge and Synthol product distribution and Table 2.11 compares their diesel and gasoline quantities. 2 The Synthol selectivities are the same as those given for run average in Table 2.6. It is immediately apparent that Arge produces more diesel and heavier fractions than Synthol. It's gasoline is of poorer quality because the molecules are mostly straight chain. However, this very same molecular characteristic gives it good diesel products because of the good cetane numbers attained. 33 
Table 2.10. Comparison of Arge and Synthol Processes 12

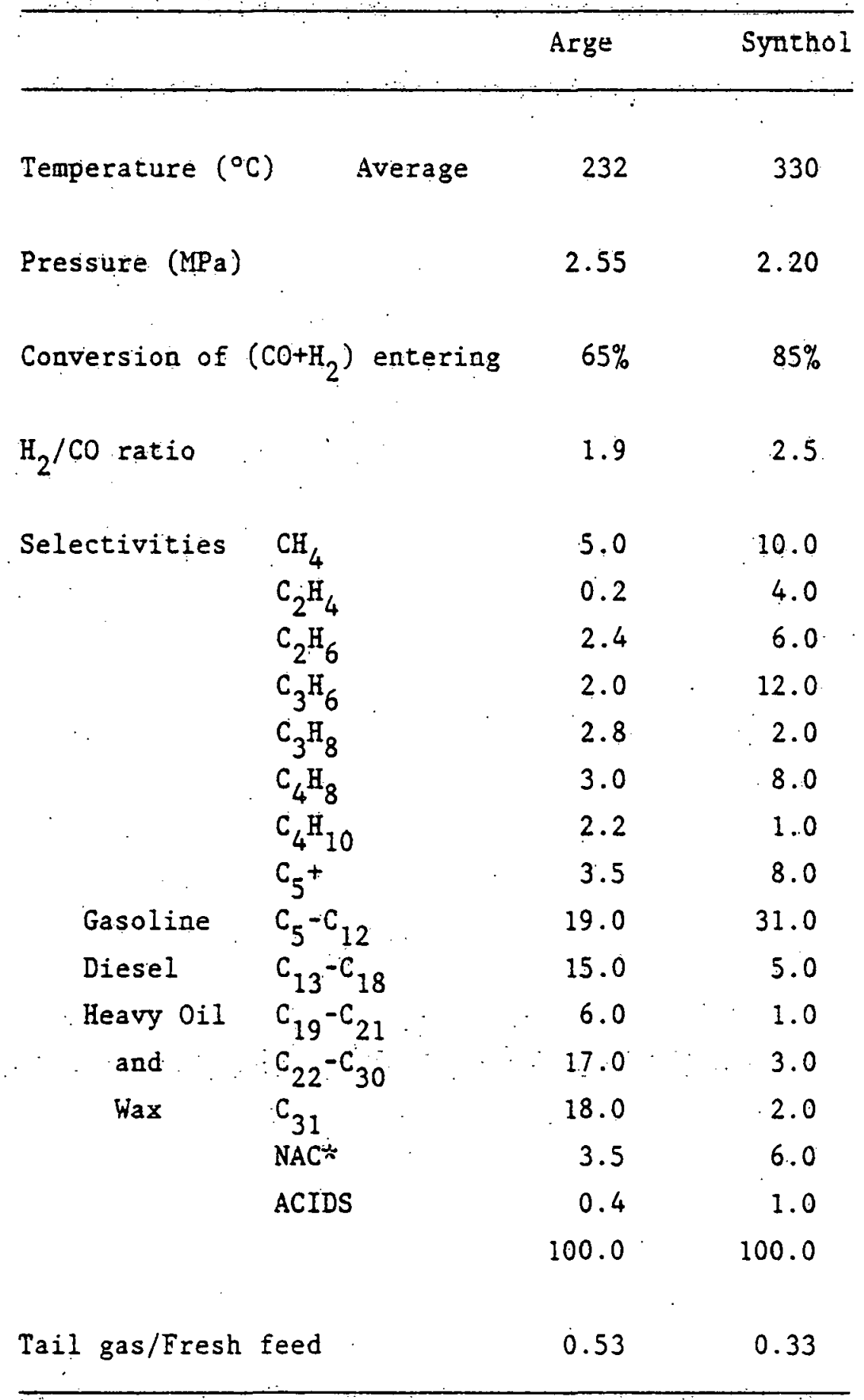

* NAC - Non-Acid Chemicals 
Table 2.11. Comparison of Arge and Synthol gasoline and diesel products 33

\begin{tabular}{|c|c|c|c|c|}
\hline & \multicolumn{2}{|c|}{ Arge } & \multicolumn{2}{|c|}{ Synthol } \\
\hline & $C_{5}-C_{12}$ & $c_{13}-c_{18}$ & $C_{5}-c_{10}$ & $c_{11}-c_{14}$ \\
\hline $\begin{array}{l}\% \text { Paraffin } \\
\% \text { Olefins } \\
\% \text { Aromatics } \\
\% \text { Alcohols } \\
\% \text { Carbonyls }\end{array}$ & $\begin{array}{r}53 \\
40 \\
\therefore \quad \\
6 \\
6 \\
1\end{array}$ & $\begin{array}{r}65 \\
28 \\
\therefore \quad 0 \\
6 \\
1\end{array}$ & $\begin{array}{r}13 \\
70 \\
. \quad 5 \\
-\quad 6 \\
6\end{array}$ & $\begin{array}{r}15 \\
60 \\
15 \\
15 \\
5\end{array}$ \\
\hline $\begin{array}{l}\text { Fraction of } \\
\text { paraffins that } \\
\text { are n-paraffins }\end{array}$ & 0.95 & 0.93 & 0.55 & 0.60 \\
\hline
\end{tabular}


Arge also produces less non-acid chemicals and they are only alcohols and a small quantity of acids. 4 It will also be noted that the quantity of tail gas is over $50 \%$ of the feed gas volume for the Arge Reactors.

At the base of the reactor (Figure 2.10) the reactor wax accumulates and is pumped to the vacuum distillation unit where it is split into a waxy oil/soft wax, medium wax and hard wax. Both medium and hard waxes are hydrogenated and some hard wax is processed further to oxidized, crystalized, powdered, and super hard waxes for specialty applications. These last are mostly batch processes (Figure 2.11).

The medium wax is sold locally for the manufacture of candles, polish, etc. 23 The hard wax is an export item and a good foreign exchange earner. It goes into plastics, electrical insulation compounds, printing inks and Lubricants. 23

The hot condensate from the product/feed gas heat exchanger and the cold condensate from the product gas cooler are both processed in the atmospheric distillation unit. The products are LPG, gasoline, diesel fractions and the bottoms that joins the reactor wax for vacuum distillation. The aqueous chemical stream that also comes from the product gas cooler is sent to the chemical recovery section in the Synthol area to be refined. The IPG stream is also refined in the Synthol area.

Provision had been made for a heptane wash to remove $\mathrm{C}_{3} / \mathrm{C}_{4}$ components and a methanol "small Rectisol" wash for the removal of $\mathrm{CO}_{2}$ from the tail gas. Since the Arge tail gas now is a prime constituent of the industrial gas stream sold to Gascor, these units are no longer used. Their cost of operation was too high to be justified by the product refinements that were no longer needed. The tail gas composition is given in Table 2.12. If 


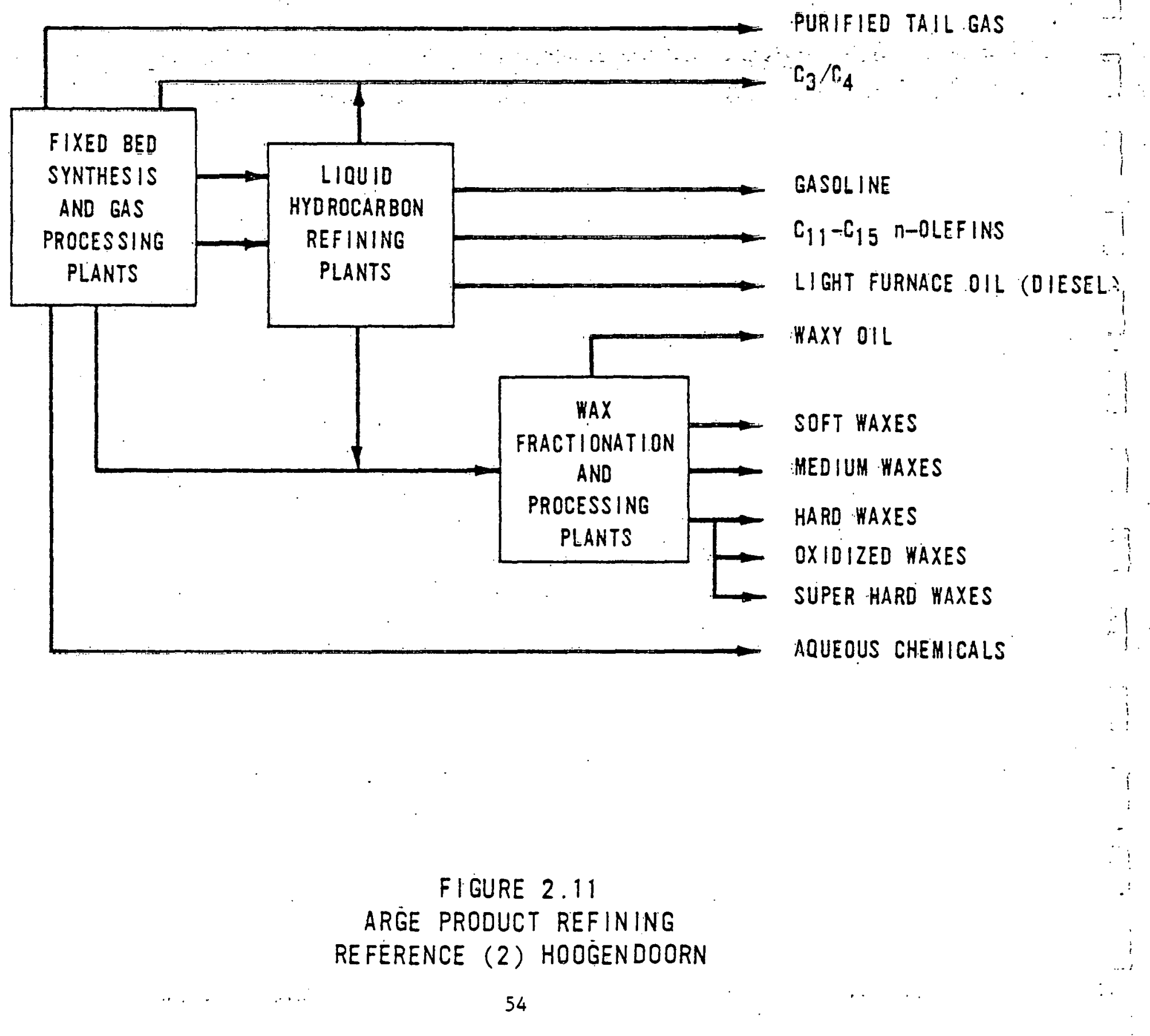


Table 2.12. Arge tail

$$
\text { gas composition } 20
$$

\begin{tabular}{lc}
\hline & \\
$\mathrm{H}_{2}$ & $47 \%$ volume \\
$\mathrm{N}_{2}$ & $2 \%$ \\
$\mathrm{CO}$ & $22 \%$ \\
$\mathrm{CO}_{2}$ & $1 \%$ \\
$\mathrm{CII}_{4}$ & $28 \%$ \\
$\mathrm{C}_{2}-\mathrm{C}_{4}$ & Trace \\
Energy content HHV & $19.0 \mathrm{MJ} / \mathrm{m}^{3}$ \\
\hline
\end{tabular}


necessary the pressure of this stream can be boosted so that it may be routed to the gas blending station or the reformers.

Although the Arge units were originally designed to produce 11,000 tonnes of product/year per reactor, their production lias been increased uver the years to $20,000-25,000 \mathrm{t} / \mathrm{reactor}$ year. ${ }^{34}$ With high reactor availability this puts total produrtinn for the area at $95,0 n n-12 n$, nnn $+/$ year. nf this $30,000 \mathrm{t} /$ year, ${ }^{5}$ are various hard waxes and $10-12,000 \mathrm{t} /$ year is medium wax. However, Sasol considered this about the upper limit for these reactors and views any efforts to increase the production per reactor as a major task. $12,34 \ldots$

2.6 SHIFT CONVERSION, AMONIA SYNTHESIS AND FERTILIZER

As they were run the early $1960^{\prime} \mathrm{s}$, the Synthol F-T units formed a closed gas loop. Pure gas from Rectisol and tail gas from the Arge units were added to the loop as feed to the reformers while liquid products were removed from the system. Some Synthol tail gas went to the fuel gas system. There was constant concern that there should be an adequate purge from the loop so that the nitrogen and argon levels would not build up. 4

An ammonia synthesis unit and associated nitric acid and ammonium nicrace plancs were erected in 1963:35 Synthol tall gas seemed a most appropriate feed stream because it contained about $50 \%$ hydrogen and it would provide a purge for the Synthol-reformers loop. However, another supply of hydrogen was also installed - the shift converter. 22 
About $20,000 \mathrm{~m}^{3} / \mathrm{h}$ of pure gas from whichever of the Arge or Synthol pure gas headers has an excess, are fed to the shift converter where steam is added to the mixture to push the shift reaction to the hydrogen side - straightforward Le Chatelier's Principle.

$$
\mathrm{H}_{2}+\mathrm{CO}_{2}+\mathrm{H}_{2} \mathrm{O}+\mathrm{CO}
$$

The hydrogen content increases while the $C O$ content is reduced to practically zero." After cooling the product gas and condensing the excess water the shifted gas is joined by the purge stream from the Synthol loop. Approximately $5-10,000 \mathrm{~m}^{3} / \mathrm{h}$ is the net purge. ${ }^{22}$

The first stage of the gas preparation for ammonia synthesis is the removal of the $\mathrm{CO}_{2}$ that is present. A Vetrocoke unit does this with an arsenical potassium carbonate wash. Next the gas enters a cold box where a series of heat exchangers cools the gas until all components except hydrogen are liquid. Components removed are methane and any other light hydrocarbons that may be present. These hydrocarbons are used either in the blending of industrial gas, factory fuel gas or as feed to the reformers. There is also a liquid nitrogen wash that is to remove traces of carbon monoxide to the flare. Finally the pure hydrogen is expanded back out through" the heat exchangers thereby making use of the Joule-Thompson effect to aid cooling.

The hydrogen is mixed in a $3: 1$ ratio with aitrogen which is available in large quantities as a byproduct of the manufacture of oxygen. This mixture is compressed to $48 \mathrm{MPa}$ and combines to form ammonia in the presence of an iron catalyst. 7 
Some of the ammonia is sold as anhydrous product. Some is oxidized using either air or oxygen to nitric acid over a platinum catalyst. This is combined with the rest of the ammonia to make ammonium nitrate. In turn, some of this is sold while the remainder is treated with limestone in a prilling tower to make limeslune amwuim uitrate fur fertilizer. The total produetion for the area is about 50,000 tonnes of nitrogen ${ }^{1}$ per year but the mix of products varies greatly. The flow sheet for the area is given in Figure 2.12.

Considering that Gascor was only formed in $1964^{35}$ and that the first gas was distributed in 1966 the growth of the market for this product has been remarkable - $20 \%$ per year up until 1975 .

There was about a 4\% dip in consumption in 1977 because of an economic downturn but the growth rebounded with sales up $9 \%$ in 1978 and $11-12 \%$ in 1979.5 This is despite a retail price rise from $\mathrm{R} 1.60 / \mathrm{GJ}$ in $1975^{22}$ to $\mathrm{R} 2.74 / \mathrm{GJ}$ in $1979 .^{5}$ With gas sales presently running at $R 45-50$ million/year ${ }^{5}$ this would indicate an average gas volume distribution of about $100,000 \mathrm{~m}^{3} / \mathrm{h} . \quad(R 1.00=\$ 1.33)$

The pipeline is about $175 \mathrm{~km}$ from the Sasol One site to the furthest end but high pressure transmission pipelines and major distribution lines stretch for $440 \mathrm{~km} .^{5}$ Some 490 customers are tied into the system with the Johannesburg gas works in turn serving numerous domestic, commercial and industrial customers. ${ }^{36}$ It is not surprising that Gascor has achieved such a tremendous growth in sales. Within $200 \mathrm{~km}$ of Sasolburg lies about half of South Africa's industry. The gas which, except for stenching agents, is essentially sulfur-free, is a very desirable fuel. The supply has been interrupted only once, for 40 hours, after the April 1975 methane reforming plant explosion. When Sasol Two eventually ties into the system the supply will be even more assured. Major users are in the glass, food processing, steel processing and ceramics industries. 


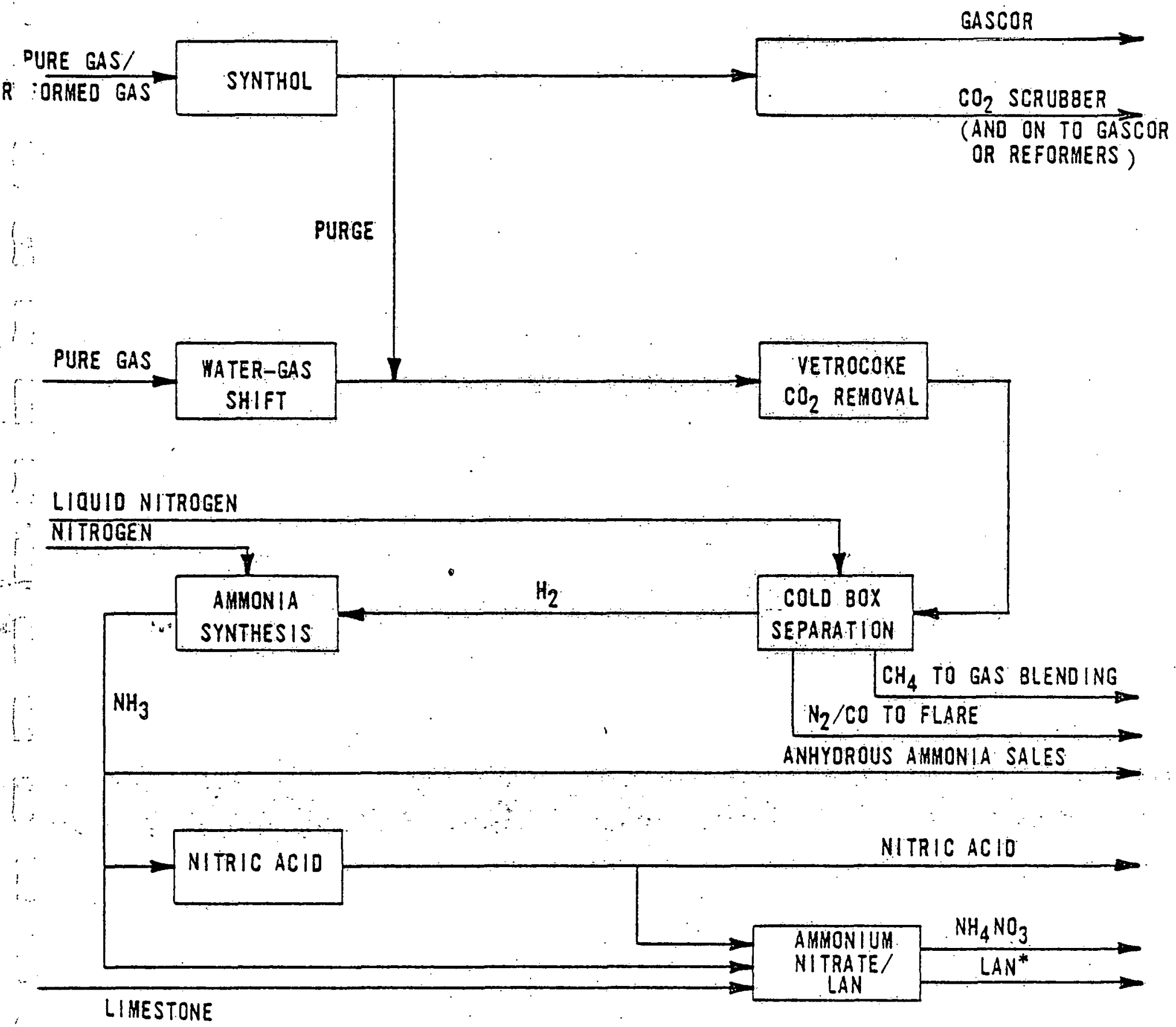

* lan - limestone ammonium nitrate

FI GURE 2.12

SHIFT CONYERTER, AMMONIA, FERTILIZER

AND SYNTHOL LOOP

REFERENCE (37) PAY 
Unfortunately for Sasol One the demand for industrial gas is not uniform even though Gascor's tariff structure favors constant load customers. ${ }^{5}$ Figure 2.13 indicates the day-to-day fluctuations in demand while Figure 2.14 shows the same thing on a seasonal basis using monthly averages. 37 There are also changes in the demand williu a day but, by judicious selection of an average flow rate for the day, these can be absorbed by letting the line pressure vary (line packing). The low weekend gas demand can be attributed to a large number of industries shutting factories down on Friday evenings and restarting on Monday morning. The seasonal changes can be correlated to the changes in average ambient temperature throughout the year in the southern hemisphere.

of all the fluctuations that cumulatively affect the demand for gas the week day/weekend change has the most drastic effect on the operation of Sasol One. Until gasifiers 14 through 16 were installed there was constant jockeying of synthesis units to make sure that all the gas that was produced was used effectively and that the industrial gas demand was always met. At the same gasifier output it was always possible to run more F-T synthesis reactors during weekends than on week days because tail gas was redirected from gas blending to methane reforming. Due to the relative profitability of the three different synthesis areas gas was normally sent to ammonia synthesis first, then Arge and finally Synthol. 37 However, the reactor capacities and turn down capabilities of Arge and Synthol are such that there are times when Arge units would be taking up the slack instead of the Synthol units. Figure 2.15 shows that there is a range of feed flow rates that exceed the maximum capacity of one Synthol reactor but fall short of the minimum feed rate for two reactors. If the gas in excess of one Synthol reactor's capacity cannot be used elsewhere than an Arge reactor must be shutdown and its feed shifted to the Synthol area so that the second Synthol reactor can be brought on line. Arge reactors are smaller and are more easily switched on or off. 


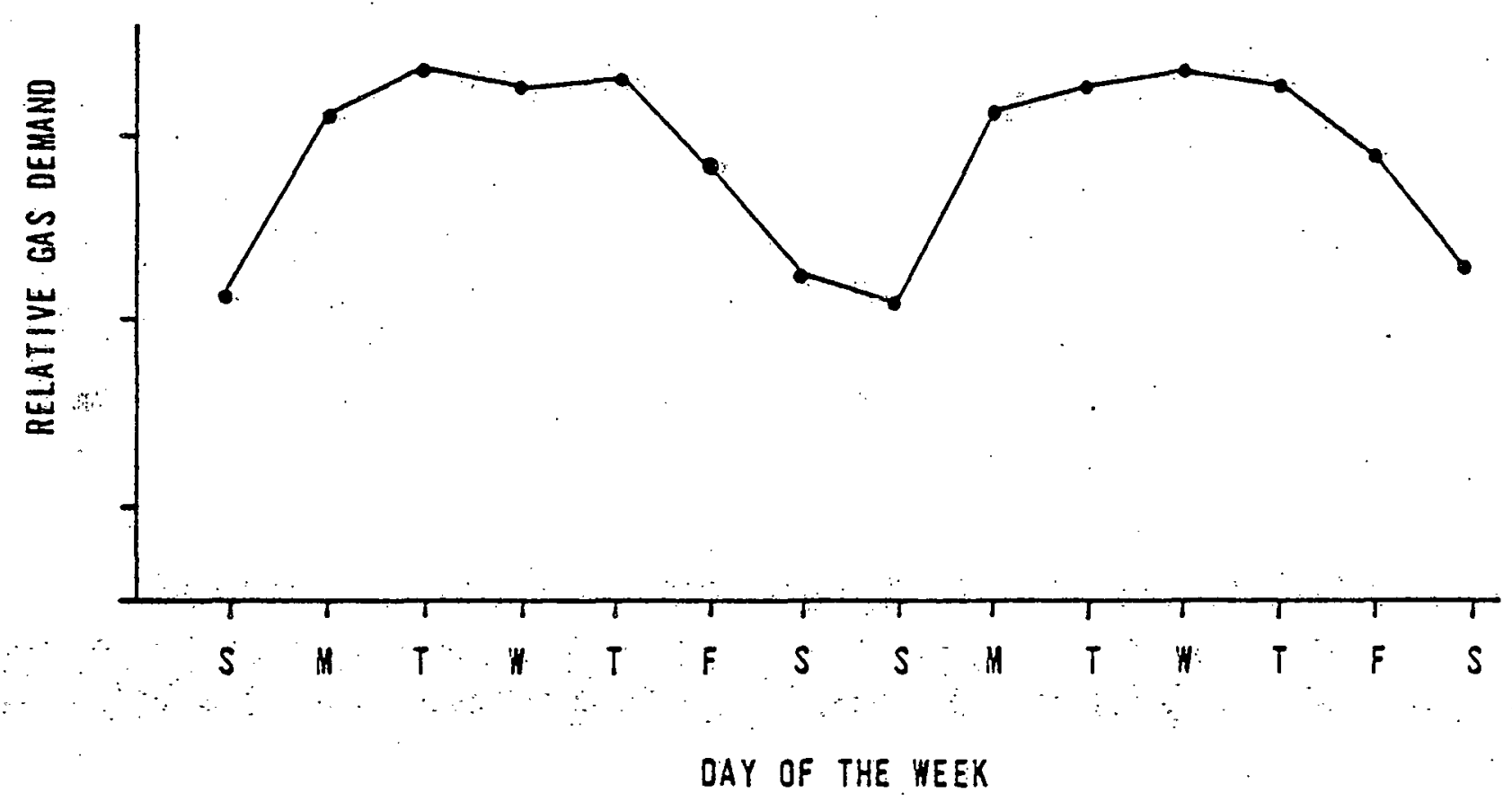

FIGURE 2.13

DAILY FLUCTUATIONS IN GAS DEMAND

REFERENCE (37) PAY 


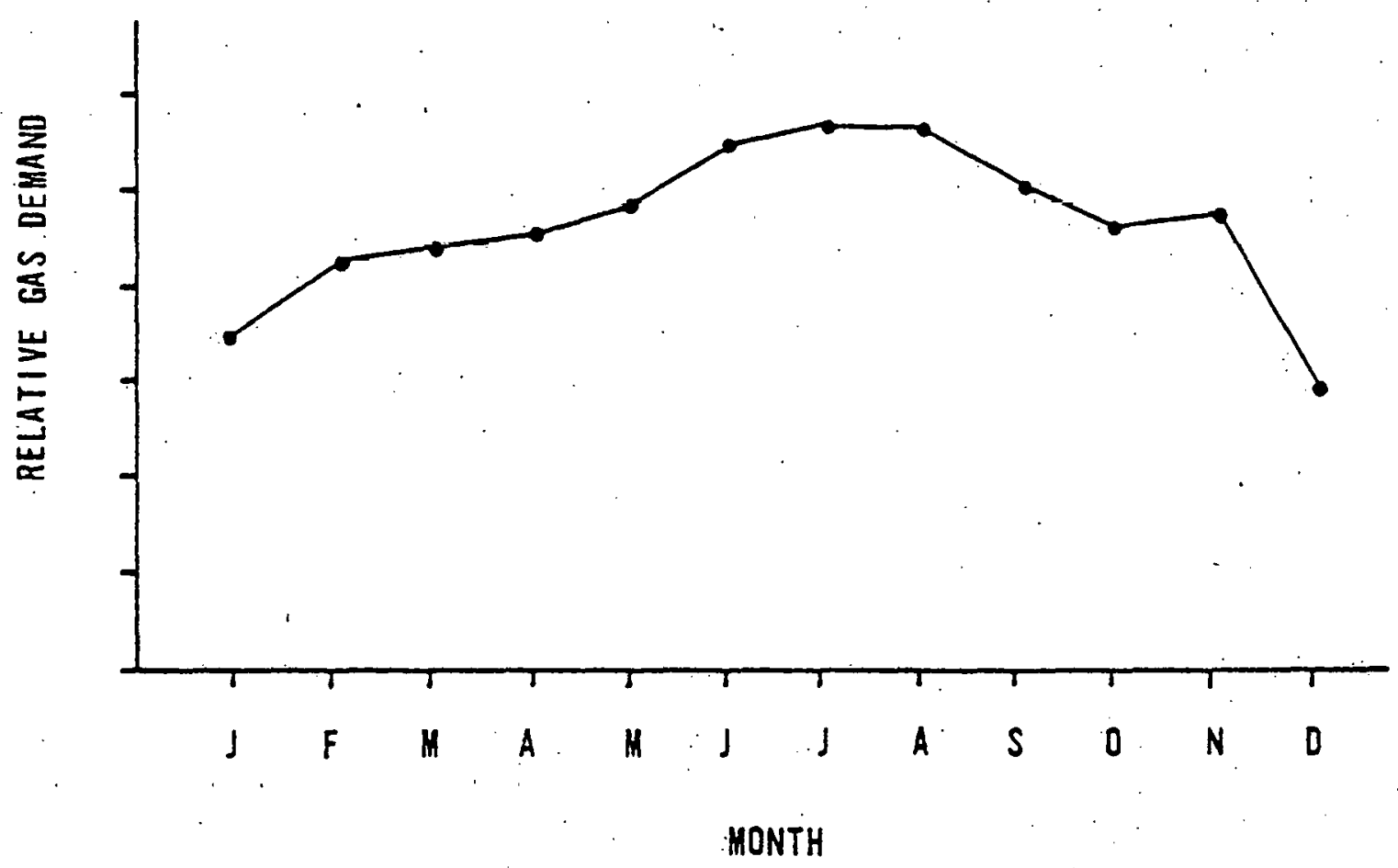

FIGUURE 2.14

SEASONAL FLUCTUATIONS IN GAS

REFERENCE (37) PAY 


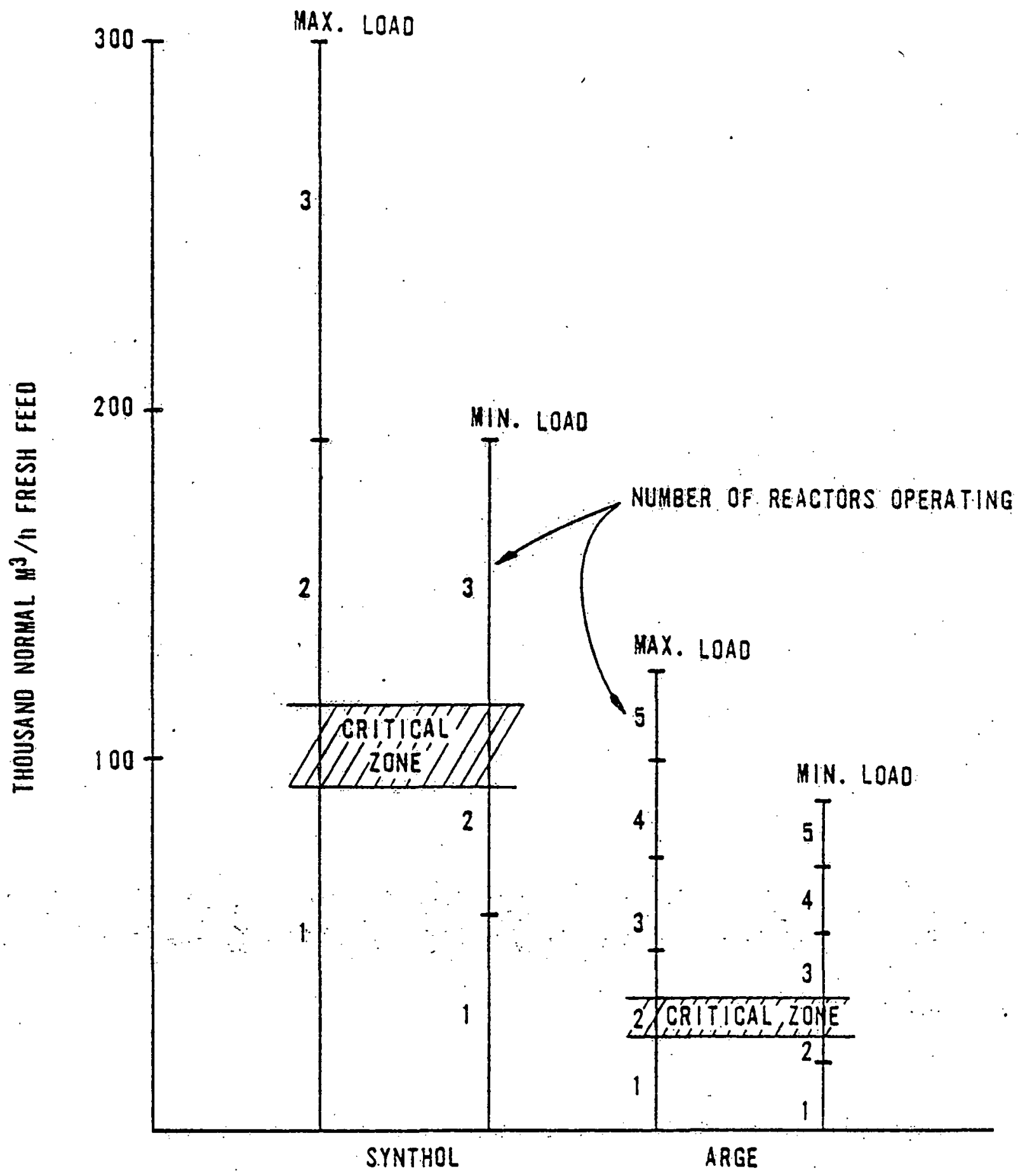

FIGURE 2.15

SYNTHOL AND ARGE CAPACITIES

REFERENCE (37) PAY 
The industrial gas is a blend of Arge and Synthol tail gases, pure gas, cold box methane and some minor amounts of IPG. Table 2.13 gives the energy contents of the gases. Normally all the Arge tail gas and most of the cold box methane with large amounts of Synthol tail gas and pure gas are blended into the industrial gas. 'IPG is used uuly if there is no other way of echicving the energy content by changing the proportions of the components already in the mixture. 38 One such time is during the biennial shutdown of the Rectisol and synthesis units. Then there is only a limited amount of pure gas and little or no tail gas to meet the demand.

Not only must the energy content of the gas be $20 \mathrm{MJ} / \mathrm{m}^{3}(500 \mathrm{Btu} / \mathrm{scf})$ but other specifications must be met. The Wobbe number and flame speed factor of the mixture have to be such that combustion at the burners is complete and there is no flame liftoff of flashback. There are also upper limits on the amounts of carbon dioxide, nitrogen and argon allowed in the blend.

All the streams than can go into the blend except Synthol tail gas are normally considered dry. In order to get any water out of the Synthol tail gas molecular sieves were added to the gas path. The Synthol tail gas also has the option of being scrubbed with high pressure water to remove the $\mathrm{CO}_{2}$. This does not affect the energy content of the gas very much because the small amounts of $C_{3}$ and $C_{4}$ hydrocarbons in the gas are lost through condensation in the scrubbers. However, other buring characteristics can be affected.

Since the three Mark 4 gasifiers and associated gas production equipment have been added to the gas circuit at Sasol one, ${ }^{2}$ the demands for industrial gas can be met comfortably together with full utilization of all the synthesis units. It is now the gasifiers that will be underutilized. 
Table 2.13. Industrial gas blending components and their energy contents

\begin{tabular}{ll}
\hline Pure gas & $16 \mathrm{MJ} / \mathrm{m}^{3}$ \\
Arge tail gas & $19 \mathrm{MJ} / \mathrm{m}^{3}$ \\
Synthol tail gas & $22-26 \mathrm{MJ} / \mathrm{m}^{3}$ \\
Cold box methane. & $37 \mathrm{MJ} / \mathrm{m}^{3}$ \\
LPG & $95-130 \mathrm{MJ} / \mathrm{m}^{3}$ \\
\hline
\end{tabular}


With Gascor sales increasing rapidly the storage capacity of the pipeline network, in terms of hours of supply, has diminished.

To counteract this Sasol installed a gas compressor on the line at Sasol One to boost the line pressure from $2.0 \mathrm{MPa}$ to 4.0-5.0 MPa.

Consideration has also been given to increasing the energy content of the industrial gas, possibly through methanation. However, with the blending components that are now available and those planned for the future there is no need.

2.8 OXYGEN, NITROGEN, STEAM AND WATER

Oxygen production at Sasol One is from eight linde oxygen units with a potential output of $100,000 \mathrm{~m}^{3} / \mathrm{h}$ of $98 \%$ pure $\mathrm{O}_{2}$ at $2.9 \mathrm{MPa}$. The six older units each produce about $10,000 \mathrm{~m}^{3} / \mathrm{h}, 39$ the seventh $15,000 \mathrm{~m}^{3} / \mathrm{h}$ and the eighth, which was added in the $1976 / 77$ gas production expansion scheme, $25,000 \mathrm{~m}^{3} / \mathrm{h}$. Steam consumption on the seven older units is about $20,000 \mathrm{~kg} / \mathrm{h}$ for each unit and it is used to drive the air and oxygen compressors for each unit. ${ }^{13}$ The newest unit uses electrical drives rated at $12.5 \mathrm{MW}$ for the air compressor and $7.5 \mathrm{MW}$ for the oxygen compressor.

Over $90 \%$ of the oxygen produced is used in gasification. Some is used in the methane reforming plant and about $1 \%$ is used in the nitric acid unit in the fertilizer area.

After the air has been compressed some is bled away for the plant air supply and more is dried and used as instrument air.

Provision is made for the recovery of some liquid oxygen and liquid nitrogen. When AECI's "Coalplex" facility (coal-based PVC) started up in Sasolburg, additional molecular sieves were fitted to all the oxygen units to prevent possible acetylene build up. 
Naturally, with oxygen units of this size, there is plenty of nitrogen to be found. Some is used as an inert utility gas in the factory. Part of the liquid nitrogen is used in the ammonia synthesis cold box to remove the last traces of $C O$ present in the feed gas. The major use is as a reactant in the ammonia synthesis unit. For this, a great deal of high $(99.9+\%)$ purity nitrogen is available.

Apart from the liquid oxygen available for sale, other liquefied gases that are available for sale are nitrogen, argon, and carbon dioxide. 23

Sasol One raises all its own steam. It also supplies high pressure steam for some of the chemical factories nearby. To do this it now has 13 boilers which are rated at 150-160 t/h each. Some $1400-1600 \mathrm{t} / \mathrm{h}$ of $3.8-4.2 \mathrm{MPa}$ steam is generated usually with 11 boilers on line. Some of the steam goes to generate the $70 \mathrm{MW}$ of electricity needed in the facility but most goes to running the gasifiers and the oxygen units. The $3.8 \mathrm{MPa}$ steam system is one of two factory wide steam networks - the other is the $240 \mathrm{kPa}$ system - and supplies energy to the turbine drives, process heat energy and process steam.

In order to reduce particulate emissions, each of the boilers was fitted with an electrostatic precipitator during 1973-1974. No attempt was made to reduce the $\mathrm{SO}_{2}$ concentration emitted from the stacks because the coal was naturally low in sulfur. However, as part of the gas production expansion scheme a $170 \mathrm{~m}$ stack replaced the small capacity $75 \mathrm{~m}$ high stack at the second power plant at Sasol One.

The high ash content of the coal did increase the problems that would normally occur in the coal pulverizing units. The high ash load also caused numerous tube failures in the steam superheated sections of the boilers. This necessitated more redundancy in equipment 2 spare boilers - and a high maintenance input. 
Water for the Sasol. One facility comes from the nearby Vaal River and its tributaries. At least $75 \mathrm{ML} / \mathrm{d}$ is needed. The majority of this is lost in evaporation from the cooling water towers. The rest is lost as process steam and water evaporated from the ash dams.

As part of a diversification in activities and to supply raw materials to the local market the Sasol Group built an olefin complex at the Sasol One site in 1964/65. A naphtha cracker was built producing $35,000 \mathrm{t} /$ year of $98 \%$ pure ethylene. It used standard technology and had four naphtha cracking turnaces. I'he ethylene was suppiied to AECI Ltd.'s Midland factory to make PVC.

Along with the ethylene unit, styrene and butadiene units were built. The former produces some $25,000 \mathrm{t} /$ year of styrene and the latter about $30,000 \mathrm{t} /$ year of 1,3-butadiene. The original intention was to recover ethylene from Synthol tail gas for the styrene plant but the cracker was a much more convenient source. The benzene for the styrene comes as impure benzol from a steel works some $20 \mathrm{~km}$ away. It is purified in a BTX unit, reacted with the ethylene to from ethylbenzene and dehydrogenated before being sold as styrene for synthetic rubber manufacture.

Originally, $C_{4}$ material for the butadiene plant came from the F-T units and the cracker. A Shell acetonitrile extractive distillation unit refined the butadiene from the $C_{4}$ mixture while a Dow unit dehydrogenated the butenes which were then recycled to the Shell unit. With the building of a second naphtha cracker in 1968, sufficient ethylene and butadiene were produced to mothball the first cracker and the Dow unit in the butadiene plant. No further F-T $\mathrm{C}_{4}$ material was needed for butadiene manufacture. 
The second cracker had a design capacity of 100,000 t/year of $9.9+\%$ pure ethylene. There were six naphtha crackers and two ethane crackers. In 1977 a co-cracker was added that could handle all-naphtha or naphtha-ethaue. Wixtures. The capacity had increased to $125,000 \mathrm{t} /$ year of ethylene. With the building of a high density polyethylene facility in the vicinity of Sasol One by Safripol, the first cracker was recommissioned in 1972 .

Numerous streams from the cracker units added to the F-T production at Sasol One. Both straight run and cat-poly gasoline were produced. $C_{3} / C_{4}$ material was blended into the IPG pool. Methane was piped into the fuel gas system. There are some products in these integrated complexes whose real origin is extremely difficult to determine. Hence the wide variation in the gasoline production reported for the Sasol One facility. The commissioning of the Natref refinery in Sasolburg in 1971 with its contributions to these pools has not made the situation any easier to resolve. 
Ever since the first Sasol facility was built in the early 1950 's, the Sasol group has returned periodically to the question of whether another such facility was required. For 20 years there was insufficient justification for one. 1 Instead increasing demands for Sasol products were met by extentions to the existing plant. Additional boilers and gasifiers, Rectisol, Synthol, Phenosolvan and oxygen units were added. A fertilizer section and an olefin complex were built, as well as a refinery. All this to the backgroud of world oil prices that remained at less than $\$ 3.00 / \mathrm{barrel}$.

When the price of oil was raised overnight to around $\$ 10.00 /$ barrel by the OPEC nations, the whole economic picture changed. South Africa was also subjected to an oil boycott by the Arab nations starting in October 1973. This boycott has never been lifted and the full impact of the boycott was lessened only because a major portion of the country's crude oil was supplied by Iran. Thus, the strategic position was also altered.

During 1974 a large effort was put into a feasibility study for a new Sasol Two facility. The results were presented to the South African government with whom the final decision lay. In December 1974 an announcement was made that a second Sasol would be built. Only later after the coal rights and land had been secured, was the actual location announced.

A grass roots facility was to be built in the Eastern Trasvaal province near the towns of Trichardt and Evander. A new town called Secunda would be developed along with the factory. It would be about $140 \mathrm{~km}$ northeast of Sasolburg and $130 \mathrm{~km}$ east of Johannesburg. Altitude and climate are very similar to Sasolburg. Iike Sasol One, Sasol Two is a mine-mouth facility. 
Figure 3.1 is the simplified overall flow diagram for the facility. ${ }^{40}$ Comparisons with the Sasol One flow diagram (Figure 2.1) immediately show that this facility has fewer different types of process units. The rationale for this was given by the ueed for transportation fuels, of which the Synthol.Fischer-Tropsch units are far more suited than the Arge fixed bed reactors. The Synthol units are also more readily scaled up in size.

Although Sasol Two was said to be a facility that was designed using proven technology, virtually every unit in the plant is different in size, process chemistry or design from the original at Sasol One. Advantage had been taken of improvements in these technologies that had occurred since Sasol One was built. Of the major process units only the gasifiers could be said to have been direct copies of equipment at Sasol One. In fact, two of Sasol Two's Mark 4 gasifiers were shipped early and installed at Sasol One when a local fabricator was unable to deliver gasifiers 15 and 16 to Sasol One. ${ }^{30}$

The construction of the facility is $100 \%$ complete (Figure $3.2^{46}$ shows the design and construction schedule). So far all or parts of units from boilers and oxygen plant through gasification, Rectisol and Synthol to the work up sections have been successfully commissioned. $41,42,43,44,45$ Problems have been minor.

3.1 COAL AND THE BOSJESSPRUIT MINE

Developed especially for supplying coal to Sasol Two, this mine lies just to the south of the factory site. It will be operated by the same Sasol One group that operates the Sigma mine. It started out. being developed around a two shaft system but is now to be a four shaft mine that will supply up to 27.5 million tonnes/year of coal to the facilities at Sasols Two and Three. ${ }^{5}$ In 1979 it was producing $170,000 \mathrm{t} /$ month mainly for the coal stockpile at Sasol Two. 41 


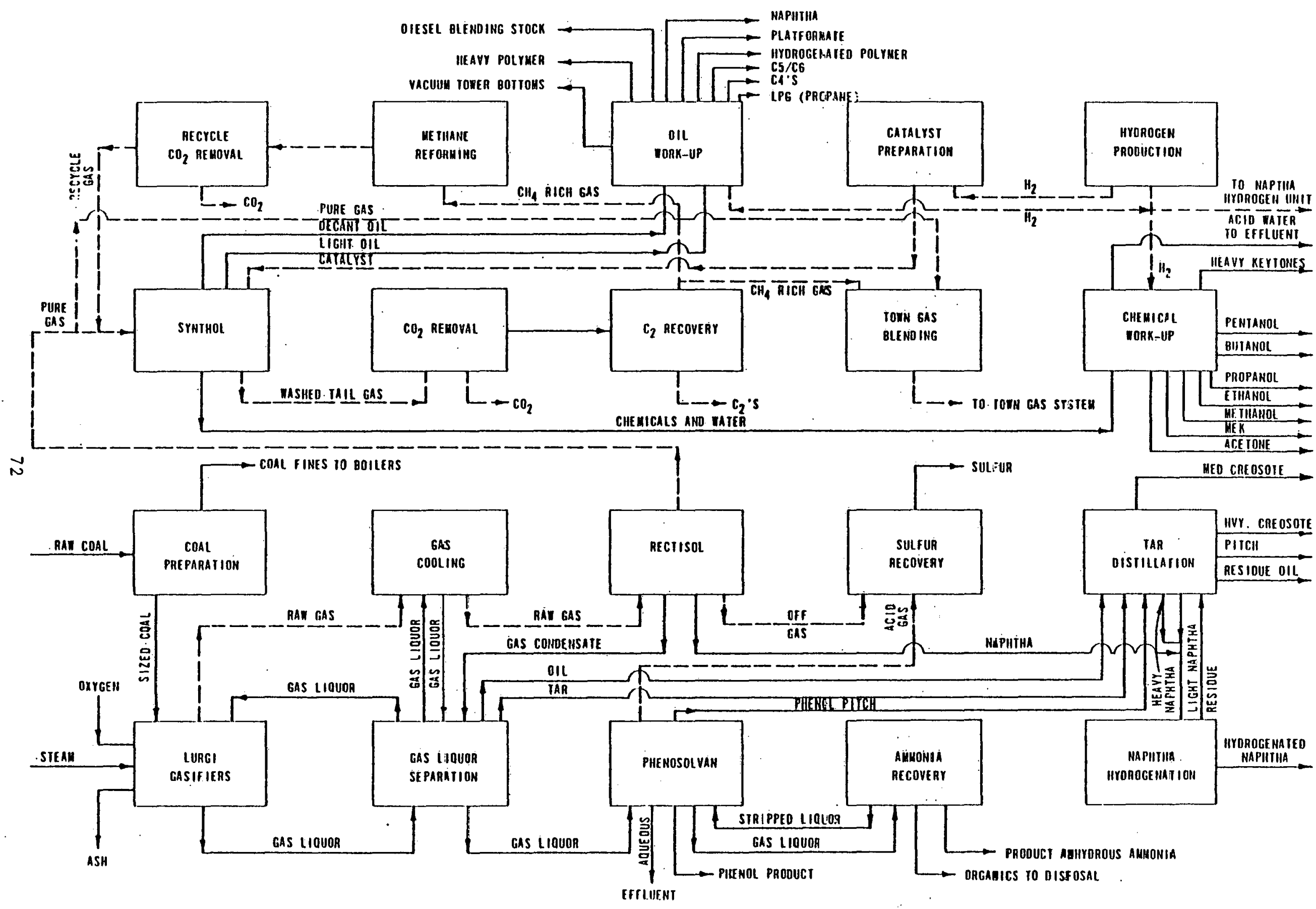


The coal is part of the Highveld coalfield. ${ }^{6}$ Seams 2,4 , and 5 are present in the area to be mined. The reserves are divided into two areas: in the main reserve area seam 4 lower is the only one mineable, while in reserve area 2 seams 4 lower and 2 are mineable. Reserve area 2 is separated from the main reserves area by a $2 \mathrm{~km}$ wide zone where no coal occurs. Seam 4 . lower varies in thickness from 0 to $5 \mathrm{~m}$ with a mean thickness of $3 \mathrm{~m}$. It is between 120 and $180 \mathrm{~m}$ below the surface. Seam 2 is $40 \mathrm{~m}$ below seam 4 lower. In reserve area 2 the thickness averages $3.7 \mathrm{~m}$. Seams 4 upper and 5 are poorly developed and do not attain mineable thickness.

Table 3.1 shows the assayed coal properties of the Bosjesspruit mine. Two things will be noted: the ash content is much lower than at Sigma and the heating value is higher. Wear on the crushers, gasifiers and boilers at Sasol Two can therefore be expected to be less than has been the case at the old facility. However, the coal is more friable and so has to be handled carefully. Wet screening is used to maintain the coal particle size during the final separation of coarse and fine material. 30 As at Sasol One the coarse material (12 $\mathrm{mm}$ ) will be gasified while the fines go to stean raising.

The mine will use both longwall and room and pillar mining methods. There will be six longwall units. 5,41 With more mechanization, more productivity can be achieved. The mine will produce five times as much coal with 6600 people as Sigma does with 1800. The life of the mine has been assessed at over 70 years. 6 . Sasol one, through wholly owned subsidiaries, owns the coal rights to 105,000 hectare and has options on about 11,000 hectare. 
Table 3.1 Bosjesspruit coạl properties $6,34,40$

Type

Moisture (as received)

Ash (moisture free)

Volatiles (moisture free)

Fixed carbon (moisture free)

Heating value

Carbon (daf)

Hydrogen (daf)

Sulfur (daf)

Nitrogen (daf)

Oxygen (daf)

Ash properties

Softening point

Melting point

Fluid point
Bituminuus

$$
\begin{aligned}
& 5.5 \% \text { wt } \\
& 22.5 \% \\
& 24.8 \% \\
& 52.7 \%
\end{aligned}
$$

$23.9-24.5 \mathrm{MJ} / \mathrm{kg}$

$79.6 \%$

$4.3 \%$

$1.3 \%$

$2.0 \%$

$13.6 \%$

$1290^{\circ} \mathrm{C}$

$1330^{\circ} \mathrm{C}$

$1360^{\circ} \mathrm{C}$ 
Each of the four shaft systems consists of an $11 \mathrm{~m}$ diameter vertical service shaft for materials and men, a $10 \mathrm{~m}$ diameter vertical ventilation shaft and a $6.4 \mathrm{~m} \times 2.4 \mathrm{~m}, 17^{\circ}$ inclined shaft for coal transport. Coal is transported to the synthetic fuels facility by conveyor.

Shaft sinking for the first part of the Bosjesspruit mine started in 1975 and in September 1979 shaft sinking began for the second pair of shafts. 41 The development costs up to 30 June 1979, including the cost of sinking two shaft systems, amount to $\$ 135$ million. Additional production equipment will have to be acquired and further : underground preproduction development will have to be undertaken at an additional ectimated coct of $\$ 1 / 0$ million to raice the production level in order that the full needs of the Sasol Two factory can be supplied.

To be able to meet the needs of the Sasol Three factory, the second two shaft system is being sunk, production equipment will have to be purchased and further underground preproduction development will have to be undertaken at a total estimated cost of $\$ 335$ million. The cost esimates are based on the cost of completion and include escalation costs. 6

3.2 GASIFICATION, PHENOSOLVAN AND TAR REFINING

The gasification unit is equipped with 36 Mark 4 Lurgi high pressure gasifiers - 30 on line and 6 standby units. 47 These gasifiers are $3.85 \mathrm{~m}$ in internal diameter and each weights some 140 tonnes. They have had two years of extensive testing at Sasol One where three identical gasifiers were installed in $1977 / 78$ and had only minor start up problems. 48 Several of the new plant's gasifiers have already been commissioned starting in October 1979.30 
Operating at 27 bar, these gasifiers are expected to produce at least 1.65 million $\mathrm{m}^{3} / \mathrm{h}$ of raw gas of composition shown in Table 3.2 , from $25,000-30,000 \mathrm{t} / \mathrm{d}$ of coal gasified in the presence of 30,000-36,000 t/d of steam and 8,000-9,000 t/d of oxygen. Snme $5000 \mathrm{t} / \mathrm{d}$ of ash will have to be disposed of. 30,50

The Phenosolvan plant will be based on the technology that is already used except that the extraction solvent will be di-isopropyl either instead of butyl acetate. ${ }^{42}$. Individual units will be bigger than at the older plants. The ammonia recovered in the Phenosolvan plant (about 120,000 tonnes per year) will be marketed as anhydrous ammonia instead of ammonium sulphate. Crude phenols will also be a product of this area.

Tars and oils separated from the gas liquor before the Phenosolvan plant will go into about 200,000 t/year of products such as creosotes, road tars, pitch and coal tar fuel. 51 The naphtha from the gasification area and the gas purification (Rectisol) will be separated from the tars and oils and hydrotreated over a catalyst to reduce the gum forming tendencies of this high octane gasoline component. 43,52

3.3 GAS PURIFICATION AND METHANE REFORMING

There will be four Rectisol trains which will purify the raw gas into about $1,100,000 \mathrm{~m}^{3} / \mathrm{h}\left(275,000 \cdot \mathrm{m}^{3} / \mathrm{h}\right.$ per train $)$ of pure gas 34 of a composition shown in Table 3.3. The solvent is methanol which in a system that operates at $-70^{\circ} \mathrm{C}$ can remove all of the unwanted components. This is done in one, three-compartment, bottle-shaped, high pressure scrubber. Each scrubber weighs 308 tonnes. These compartments are the prewash, main wash, and final wash. Refrigeration in this unit is provided by a propylene system in place of the fairly troublesome ammonia coolers at Sasol One. The first unit was commissioned in January 1980.42 
Table 3.2 Raw gas

$$
\text { composition } 40,49
$$

$\begin{array}{lr}\mathrm{H}_{2} & 38.1 \% \text { volume } \\ \mathrm{N}_{2} & 0.3 \% \\ \mathrm{CO} & 19.0 \% \\ \mathrm{CO}_{2} & 32.0 \% \\ \mathrm{CH}_{4} & 9.4 \% \\ \mathrm{C}_{2}+\cdots & 0.5 \% \\ \mathrm{H}_{2} \mathrm{~S} & 0.7 \% \\ \mathrm{C}^{2} & \end{array}$


Table 3.3

Pure gas composition -

Sasol Two 40,49

\begin{tabular}{lc}
$\mathrm{H}_{2}$ & $56 \%$ by volume \\
$\mathrm{CO}$ & $28 \%$ \\
$\mathrm{CO}_{2}$ & $1.5 \%$ \\
$\mathrm{CH}_{4}$ & $13.5 \%$ \\
$\mathrm{C}_{2} \mathrm{H}_{4}$ & $0.02 \%$ \\
$\mathrm{C}_{2} \mathrm{H}_{6}$ & $0.20 \%$ \\
$\mathrm{~N}_{2}$ & $0.08 \%$ \\
$\mathrm{~A}$ & $0.46 \%$ \\
$\mathrm{~S}$ & $0.07 \mathrm{ppm}$ \\
\hline
\end{tabular}


The absorbed gases will eventually be routed to Stretford units to recover some 90,000 tonnes/year of elemental sulfur. 34

The methane reformer feed will be completely derived from the Synthol tail gas after cryogenic separation. The eight partial oxidation methane reformers will receive a total feed of $225,000 \mathrm{~m}^{3} / \mathrm{h}$ of gas containing $90 \%$ methane. While consuming 3400 tonne/d of oxygen in the reformers will produce $550,000 \mathrm{~m}^{3} / \mathrm{h}$ of reformed gas with a methane content of $4 \%$. $^{34}$

The reformed gas will join with the pure gas from the Rectisol area to make up the Synthol fresh feed. This totals 1.6 million $\mathrm{m}^{3} / \mathrm{h}$ and is well beluw 1.9 million $\mathrm{m}^{3} / \mathrm{h}$ eoeal gas feed fur seven Syntho] reactors. 34 Now that an eighth reactor is being built $^{43}$ there is likely to be an even bigger discrepancy. The assessment is that the gas production rate of the gasifiers is likely to be above that quoted. ${ }^{34}$. Judging by the figures quoted for the gas production expansion scheme at Sasol One, ${ }^{12}$ three Mark 4 gasifiers will generate about $130,000 \mathrm{~m}^{3} / \mathrm{h}$ of pure gas and so about 1.3 million $\mathrm{m}^{3} / \mathrm{h}$ of pure gas can be expected from 30 gasifiers. This would make a better balance.

3.4 SYNTHOL SYNTHESIS

When it came to choosing the synthesis units for the facility the unknowns were not the same as those that had confronted Sasol in the 1950's. Both Synthol and Arge reactors had been operated since 1955. The choice depended more on the spectrum of products required and the ease of scaling up the design. Catalyst composition and plant operating conditions could determine the product spectrum so the ease of scale up became the deciding factor. 26 
Sasol considers the Arge reactors at Sasol One to have reached the limit of their operating capacity and that enlarging the reactor to achieve higher capacity would require a major design and development effort. With the cooperation of Lurgi, Sasol is studying how the fixed bed reactor system can be improved to achieve higher capacities. 12 However, the option is a long term one and could not be considered for Secunda. As upward of 50 existing size reactors would be needed, Arge F-T process was not considered.

The initial target was eight to ten Synthol reacturs and The Badger Company, Inc. of Cambridge, MA was enlisted to help with the scale up of the design. 29,53 Eventually, seven reactors were decided on with the idea that six would be operating at any time. Each had the capacity to process about $300,000-350,000 \mathrm{~m}^{3} / \mathrm{h}$ of fresh feed (pure gas and reformed gas). However, and it is not apparent on the August 1979 photographs of Sasol Two, an eighth reactor is now being installed. ${ }^{43}$ Provision had always been made in the designs to install it and the structural steel was already in place. Apparently the February 1979 decision to build Sasol Three also prompted a decision to install the eighth Synthol at Sasol Two. There is every likelihood that the two years of experience with the Mark 4 gasifiers at Sasol One has indicated that the 36 gasifiers at Sasol Two would produce more gas than was originally anticipated - possibly $50,000 \mathrm{~m}^{3} / \mathrm{h}$ of pure gas per gasifier or $1,500,000 \mathrm{~m}^{3} / \mathrm{h}$ of pure gas if 30 are on line.

The Synthol reactors are about $75 \mathrm{~m}$ high and the actual reactor vessels are about $3 \mathrm{~m}$ in diameter. Their general appearance is very similar to the units in Sasolburg. The serpentine cooling coils that were fitted to. the $C$ reactor at Sasol One are used. There is also great likelihood that they will incorporate the periodic catalyst removal and addition that has been successfully tested on the old $C$ reactor. 30 
The carbon conversion selectivity is given in Table $3.4^{50}$ and is the mass percentage of carbon converted from feed $\mathrm{CO}$ and $\mathrm{CO}_{2}$ to the product indicated. It is anticipated that percentage conversion of $\mathrm{CO}$ and $\mathrm{CO}_{2}$ will be about $85 \%$ and that the tail gas/fresh feed ratio will be about 0.33 .

The first test run was carried out successfully in March 1980.46

Catalyst for the reactors is iron based and is prepared at the Sasol Two site. The finely powdered catalyst is pneumatically conveyed to the catalyst reduction plant for the final treatment step before being loaded into the Synthol reactors. The reduction plant has three reactors that hydrogenate the catalyst in a fluidized bed to reduce the catalyst. The active reduced catalyst is transferred to the Synthol units pneumatically with nitrogen. ${ }^{43}$

Each Synthol reactor train consists of a reactor where products are formed, a feed gas compressor and heat exchangers that preheat the feed gas and cool the products. Heavy oil is separated out in a hot quench tower which also oil-scrubs any catalyst which may have escaped from the reactor with the product gas. Separation of the light oil, aqueous fraction and tail gas takes place in a separator drum. The products have to be stabilized before being sent to the product refinery.

Decanted oil clean-up is more sophisticated than the treatment used at Sasol One. The heavy oil catalyst containing is depressurized to remove dissolved gases, cooled, and pumped into a large decanter with a rotating rake. Catalyst solids settle to the bottom while clean oil is decanted from the top of the vessel. The concentrated catalyst slurry is pumped through a pressure filter. The cleaned oil filtrate is then sent to the refinery for further processing. ${ }^{43}$ 
Table 3.4 Product Selectivity for the Sasol Two Synthols ${ }^{50}$ (mass \% basis)

Methane

11.0

Ethane/Ethylene

7.5

Propane/Propylene

13.0

Butanes/Btuylenes

11.0

$\mathrm{C}_{5}$ to $375^{\circ} \mathrm{F}$ fraction

37.0

$375^{\circ} \mathrm{F}$ to $750^{\circ} \mathrm{F}$ fraction

11.0

$750^{\circ} \mathrm{F}$ to $970^{\circ} \mathrm{F}$ fraction

3.0

Heavier than $970^{\circ} \mathrm{F}$ fraction

0.5

Chemicals

$\frac{6.0}{100.0}$ 
It is in this section of the synthetic fuels facility that the biggest differences in flow sheet occur between Sasol One and Sasol Two. Because of the sheer size of the venture there are components in the tail gas streams from the Synthol reactor trains that are present in sufficiently large quantities to make recovery economically viable. Ethylene has been the focus of most of this attention.

It is anticipated that some 185,000 tonnes of ethylene/year will be available. ${ }^{34}$ This exceeds the combined capacity of the two naphtha based ethylene units in. Sasolburg. "It is likely that one or both will be mothballed until the demand again catches up with the supply. In order to get the ethylene to the plastics manufacturers in the Sasolburg area a $140 \mathrm{~km}, 12-16^{\prime \prime}$ diameter pipeline has been laid from Secunda. The ethylene is produced in a cryogenic separator.

Before undergoing cold separation all traces of carbon dioxide must be removed from the combined tail gas streams eminating from the Synthol reactor trains. This is achieved using a chemical absorbent. The scrubbing towers involved, and there are several, are up to $71 \mathrm{~m}$ tall.

Once the carbon dioxide has been removed, various components of the Synthol tail gas are separated in the cold box. Product gases are hydrogen, methane, ethane, ethylene and higher hydrocarbons. The hydrogen is used in many hydrogenation processes to improve the product quality. It can also be returned to the Synthol reactors if there is no other use for it. Provision has been made in the design to allow a hydrogen/methane mixture to be sold as industrial gas but this option has not yet been exercised.

The $90 \%$ pure methane 34 is routed to the methane partial oxidation reformers to provide further feed for the synthol reactors. It can also be used as fuel gas. 
The ethylene and ethane stream is sent to the ethylene area where ethylene of high purity is separated out in a $\mathrm{C}_{2}$-splitter. The ethane that remains is cracked at high temperature in three ethane cracking furnaces. The ethylene produced is purified and dispatched to Sasolburg through the pipeline. 43

The $C_{3} / C_{4}$ mixture is routed to the catalytic polymerization unit where both cat-poly gasoline and diesel fuel are produced. This is a departure from Sasol One practice but the mix of transportation fuels required for the South African market dictates that efforto be made to increase the diesel yield. Eight reactors and two fractionation trains are required. The propane and butane that is untouched by the cat-poly units is recovered and blended into IPG or used for Reid vapor pressure (RVP) adjustment of the gasoline. ${ }^{43}$

Liquid hydrocarbons produced in the Synthol process are treated in a series of processes in the oil work-up area. Because Sasol Two will be supplying up to $25 \%$ of the transportation fuels for the South African market, it is necessary to do more up-grading of the product than is the case at Sasol One. The latter is responsible for meeting less than $5 \%$ of the demand with oil-from-coal. The final products from Sasol Two must enter the market place with the same quality as the crude oil based fuels that they will be replacing.

In the oil work-up area the processes that are found are light oil fractionation, vacuum distillation, a distillate hydrotreater unit, a distillate selective cracking unit and a platforming unit. This last uses a platinum-based catalyst that can be regenerated while the reactor is at full load. Products from this area include high grade gasoline, diesel fuel, jet and other fuels. ${ }^{43}$ Process design for this area was done by Mobil and UOP. Iinde was responsible for the cold separation unit. 54 
The chemical work-up area refines the aqueous effluent from the synthesis reactors into saleable products such as ethanol, propanol, acetone and MEK. There is some uncertainty of the quantity but it appears to be at least 85,000 tonne per year ${ }^{34}$ and may be over 100,000 tonne per year. 51

3.6 OXYGEN, STEAM AND WATER

The oxygen facility at Sasol Two is the largest in the world. L'Air Iiquide designed each of the six units to deliver up to 2275 tonnes/day of $98.5 \%$ pure oxygen at $3.4 \mathrm{MPa}{ }^{55}$ As the total oxygen requirement for the facility is 12,000 tonne/day $(8,600$ to gasification and 3,400 to reforming ${ }^{34}$, , one of the six units will be a spare.

Each train contains the foliowing: 55

- An Air Iiquide cold box producing $70,800 \mathrm{~m}^{3} / \mathrm{h}$ of $98.5 \%$ oxygen, $22,300 \mathrm{~m}^{3} / \mathrm{h}$ of nitrogen containing $100 \mathrm{ppm}$ of $\mathrm{O}_{2}$ and $8500 \mathrm{~m}_{\mathrm{n}}^{3} / \mathrm{h}$ of dry, carbon dioxide-free air.

- An air compressor of the axi-centrifugal type, delivering $380,000 \mathrm{~m}^{3} / \mathrm{h}$ with a synchronous motor drive with variable f.requency start, $3,000 \mathrm{rev} / \mathrm{min}, 132 \mathrm{kV}, 35.3 \mathrm{MW}$.

- An oxygen compressor, centrifugal type, delivering $76,000 \cdot \mathrm{m}^{3} / \mathrm{h}$ at a discharge pressure of $3.7 \mathrm{MPa}$ with an induction motor with across-the-line start, a speed of $1500 \mathrm{rev} / \mathrm{min}, 11 \mathrm{kV}$, and $13.7 \mathrm{MW}$.

The discharge lines of the six air compressors and the suction lines of the seven oxygen compressors are cross connected, allowing great flexibility of operation. These units have been successfully commissioned. 43 
The steam generation is carried out in a Deutsche Babcock designed and built plant. ${ }^{43}$ Six boilers that each can deliver 540 tonnes/h of steam at $430^{\circ} \mathrm{C}$ and $4.0 \mathrm{MPa}$ have been erected. Recent photographs. of the facility indicate that there are two additional boilers under construction for steam to Sasol Three. ${ }^{45}$ There are four large mills per boller to pulverize the coal and each boiler has six fans to provide combustion air. An electrostatic precipitator is used on each boiler to remove $98 \%$ of the fly ash.

Electrical energy is generated from six 60 steam-driven turbo generators. However, a large portion of the electrical energy is purchased from the Electricity Supply Comisision (ESCOM) because the Sasol Two requirement is $600-700 \mathrm{MW}$

Ash from gasification and boilers is bydraulically moved to the fine ash dams and after dewatering to the coarse ash dump.

Cooling water is circulated at a rate of $165 ; 000 \mathrm{~m}^{3} / \mathrm{h}$ through the cooling water system. There are four natural draft cooling towers with bottom diameters of $105 \mathrm{~m}$ and heights of $151 \mathrm{~m}$. Water is allowed to range in temperature from 27 to $40^{\circ} \mathrm{C} .^{34}$ Blowdown from the cooling water towers is routed to the lime softeners and ultimately goes to boiler feed water. Circulating the cooling water to the power plant and oxygen plant are five, $20,000 \mathrm{~m}^{3} / \mathrm{h}$ pumps. Raw water comes from the Bosjesspruit dam which delivers a make up of about $130,000 \mathrm{~m}^{3} / \mathrm{d}$. Efforts were made in all the plant designs to minimize the water usage by making maximum use of air cooled heat exchangers. 42

\subsection{SASOL THREE}

The decision to build this facility was announced in February 1979.5 Immediately site clearing work was commenced on land adjacent to Sasol Two. Work was also begun on developing the Bosjesspruit 
mine to a four shaft system. Fluor Corporation was retained as the managing contractor. As it was intended to make Sasol Three a virtual copy of Sasol Two, orders were immediately placed for the long lead-time items of equipment. Because so much of the construction infrastructure is in place at Secunda it is anticipated that start-up shall begin in 1982.54

The intention with this third unit was to maximize motor fuel production and minimize other byproduct production. To this end Sasol and Fluor are working on a design for a plant that will hydrocrack the gasification byproducts such as creosote to diesel fuels. Fluor Engineers and Constructors have been retained for the design and engineering of this plant which will convert 360,000 tonne/year of ireasule apl pleinuls. 52

By the third quarter of 1980 the construction of Sasol. Three was $30 \%$ complete. ${ }^{46}$ 


\subsection{REFERENCES}

1. P. E. Rousseau, "The Robens Coal Science Lecture, 1975: The Coal Renaissance; A South African Point of View." Journal of the Institute of Fuel, December 1975.

2. J. C. Hoogendoorn, "The Sasol Story," Sasolburg, South Africa. Presented at the AIME 23rd Annual Meeting, Dallas, TX, Eebrilary 24, 1974.

3. J. C. Hoogendoorn, "The Sasol Energy Project," Sasolburg, South Africa. Obtained from the South African Embassy's Scientific Counselor, Washington, D.C.

4. P. E. Rousseau, "Organic Chemicals and the Fischer-Tropsch Synthesis in South Africa," Chemistry and Industry, pp. 1958-1966, 1962.

5. "Sasol," Supplement of the Financial Mail, (Johannesburg, South Africa), November 16, 1979.

6. Sasol Limited, "Prospectus in Respect of an Offer of 245,000,000 Ordinary Shares" Sasolburg, South Africa, August 15, 1979.

7. South African Coal, 0 il and Gas Corporation Limited, Sasol is ...., Sasolburg, South Africa. Obtained from the South African Embassy's Scientific Counselor, Washington, D.C.

8. J. A. Stegmann, "Embargo," Sasolburg, South Africa. Preșented at the Unisa Seminar on the Oil Crisis, Pretoria, South Africa, March 1, 1979.

9. U.S. DOE, "Coal Liquefaction at Sasol II." Washington, DC, June 1979.

10. South African Coal, $O i l$ and Gas Corporation, Limited, Annual Report 1978, Sasolburg, South Africa.

11. J. C. Hoogendoorn, "Gas from Coal with Lurgi Gasification at Sasol", Sasolburg, South Africa. Presented at the IGT Symposium on Clean Fuels from Coal, Chicago, IL, September 10-14, 1973.

12. J. C. Hoogendoorn, "Conversion of Coal into Fuels and Chemicals in South Africa," Sasolburg, South Africa. Presented at the Third International Coal Conference, Sydney, Australia, October 6-8, 1976.

13. J. C. Hoogendoorn and J. M. Salomon, "Sasol: World's Largest Oil-from-Coal Plant," Parts I, II, III and IV, British Chemical. Engineering, May, June, July, and August, 1957.

14. Sasol News/Sasolnuus, July 1980.

15. P. F. H. Rudolph, "Processing of American Coals in a Lurgi Gasifier," Frankfort, West Germany. Presented at the Sixth Synthetic Pipeline Gas Symposium, Chicago, IL, October 1974. 
16. P. F. H. Rudolph, "Synfuels from Coal. How and at what Cost?" Frankfurt (Main), Federal Republic of Germany. Presented at the Seventh Energy Technology Conference, Washington, D.C. March 24-26, 1980.

17. P. F. H. Rudolph, "The Lurgi Process. The Route to SNG from Coal" Frankfurt, West Germany. Presented at the Fourth Synthetic Pipeline Gas Symposium, Chicago, II, October 30-31, 1972.

18. IEA Coal Research, "Report of a Visit to South Africa, 27 February to 10 March, 1978." Working Paper No. 24. London, March, 1978.

19. H. L. Roberts, "Oil from Coal: The Engineering Challenge," South African Mechanical Engineer, Vol. 25, pp. 36-41, February 1975.

20. J. C. Hoogendoorn, "Experience with Fischer-Tropsch Synthesis at Sasol," Sasolburg, South Africa. Presented at the IGT Symposium on Clean Fuels from Coal, Chicago, II, September 10-14, 1973.

21. "Coal Iiquefaction, Solid-Iiquid Separation is a Major Hurdle", Liquid Filtration Newsletter, p. 3, February 5, 1980.

22. D. P. de Villiers, "Oil and Gas from Coal in South Africa." Sasolburg, South Africa. Presented at the Australian Gas Association 14th Annual Convention, Canberra, Australia, September 28-October 1, 1975.

23. South African Coal, Oil and Gas Corporation Limited, Sasol's Products and Their Applications, Sasolburg, South Africa, September 1973. Obtained from the South African Embassy's Scientific Counselor, Washington, D.C.

24. J. M. Evans, K. S. Schoultz, M. I. Cohen, and R. E. Yodaiken, Report of Trip to Sasol, Sasolburg, South Africa for NIOSH, December 5-7, 1977.

25. J. C. Hoogendoorn, "Coal Gasification at Sasol" ChemSA, pp. 123-125 August, 1978.

26. A. H. Stander, "Gasoline from Coal - A Reality," Sasolburg, South Africa. Presented at the World Coal Symposium, London, U.K., September 10-11, 1975.

27. M. E. Dry, "Project carbonization rate on iron catalyst," Hydrocarbon Processing, pp. 92-94, February 1980.

28. H. J. Cronje, "Oil from Coal", Sasolburg, South Africa, November 1974. Obtained from the South African Embassy's Scientific Counselor, Washington, DC.

29. W. C. A. Holtkamp, F. T. Kelly and T. Shingles, "Circulating Fluid Bed Catalytic Reactor for the Fischer-Tropsch Synthesis at Sasol II,", ChemSA, March 1977.

30. Sasol News/Sasolnuus, January, 1980. 
31. J. H. Govaarts and C. W. Schulte, "Low Grade Coal as a Chemical Feedstock", S. A. Chemical Processing, p. 8, October/November, 1973.

32. M. L. Poutsma, "Chemical Assessment of Advanced Process Concepts for Liquefaction of Low $\mathrm{H}_{2}$ : $\mathrm{CO}$ Ratio Synthesis Gas Based on the Kölbel Slurry Reactor and the Mobil-Gasoline Process." Oak Ridge, TN for ORNL, July, 1979, ORNL-5635.

33. J. C. Hoogendoorn, "New Applications of the Fischer-Tropsch Process," Sasolburg, South Africa, June 1975. Obtained from the South African Embassy's Scientific Counselor, Washington, D.C.

34. J. C. Hoogendoorn, "Gas from Coal for Synthesis of Hydrocarbons, Status of Sasol II." Sasolburg, South Africa. Presented at the Ninth Synthetic Pipeline Gas Symposium, Chicago,. IL, November 1, 1977.

35. S. W. Lombard, "Sasol", Parts 1, 2, and 3, Sasolburg, S.outh Africa, February 1976. Obtained from the South African Embassy's Scientific Counselor, Washington, D.C.

36. D. Clark, "South Africa's Coal Gasification: Prospects for the Future," Hydrocarbon Processing, pp. 56C-56I, January 1979.

37. T. D. Pay, "An Integrated Synthetic Fuels Facility - The Sasol I Experience," Oak Ridge, TN. Presented at the: Third World Energy Engineering Conference, Atlanta, GA, October $14-16,1980$.

38. T. D. Pay, "The Use of tinear Programming in the Sasol Oil-from-Coal Complex," Sasolburg, South Africa. Presented at the Annual Meeting of the Operations Research Society of South Africa, Johannesburg, South Africa, November 1975.

39. "Oil from Coal in South Africa," The Engineer, January 23, 1953.

40. J. G. Kronseder, "Sasol II: South Africa's Oil-from-Coal P.lant." Hydrocarbon Processing, pp. 56F-56NN, July 1976.

41. Sasol News/Sasolnuus, November 1979.

42. Sasol News/Sasolnuus, February 1980.

43. Sasol News/Sasolnuus; March 1980.

44. Sasol News/Sasolnuus, June 1980.

45. Sasol'News/Sasolnuus, August 1980.

46. Sasol Limited "Chairman's review for the year ended 28 June 1980" Sasolburg, South Africa. Published in the Natal Mercury, Durban, South Africa, September 26, 1980 . 
47. "Sasol Pushes Licensing of Coal Process," Oil and Gas Journal, pp. 108-109, September 10, 1979.

48. P. F. H. Rudolph, "Status of Coal Gasification and what is New in The Ficld," ChemsA, pp. 156=169, October 1978.

49. M. Heylin, "South Africa Commits to Oil-from-Coal Process," C\&EN, pp. 13-16, September 17, 1979.

50. J. C. Hoogendooru and S. B. Jackson, "Sasol Irojects in South Africa," Sasolburg, South Africa and Irvine, CA. Presented at Coal Technology '79.

51. J. C. Hoogendoorn, "Gas from Coal for Synthesis of Hydrocarbons," Sasolburg, South Africa. Presented at the 112 th Annual General Meeting of the Institution of Gas Engineers, London, U.K., May 1975.

52. Chementator, Chemical Engineering; January $14,1980$.

53. "South African Synfuels - A Blueprint for the U.S." ENR, pp. 10-11, September 13, 1979.

54. Fluor Corporation, "Sasol Two and Sasol Three Facts." Irvine, CA, August, 1979.

55. F. Worff, D. V. Eyre and M. R. Grenier, "Oxygen Plants: 10 Years of Development and Operation," CEP, pP. 83-87, July 1979. 